\title{
The emerging technology of biohybrid micro-robots: a review
}

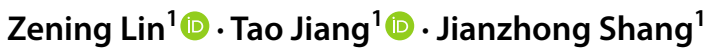

Received: 18 November 2020 / Accepted: 10 April 2021 / Published online: 16 May 2021

(c) The Author(s) 2021

\begin{abstract}
In the past few decades, robotics research has witnessed an increasingly high interest in miniaturized, intelligent, and integrated robots. The imperative component of a robot is the actuator that determines its performance. Although traditional rigid drives such as motors and gas engines have shown great prevalence in most macroscale circumstances, the reduction of these drives to the millimeter or even lower scale results in a significant increase in manufacturing difficulty accompanied by a remarkable performance decline. Biohybrid robots driven by living cells can be a potential solution to overcome these drawbacks by benefiting from the intrinsic microscale self-assembly of living tissues and high energy efficiency, which, among other unprecedented properties, also feature flexibility, self-repair, and even multiple degrees of freedom. This paper systematically reviews the development of biohybrid robots. First, the development of biological flexible drivers is introduced while emphasizing on their advantages over traditional drivers. Second, up-to-date works regarding biohybrid robots are reviewed in detail from three aspects: biological driving sources, actuator materials, and structures with associated control methodologies. Finally, the potential future applications and major challenges of biohybrid robots are explored.
\end{abstract}

\section{Graphic abstract}

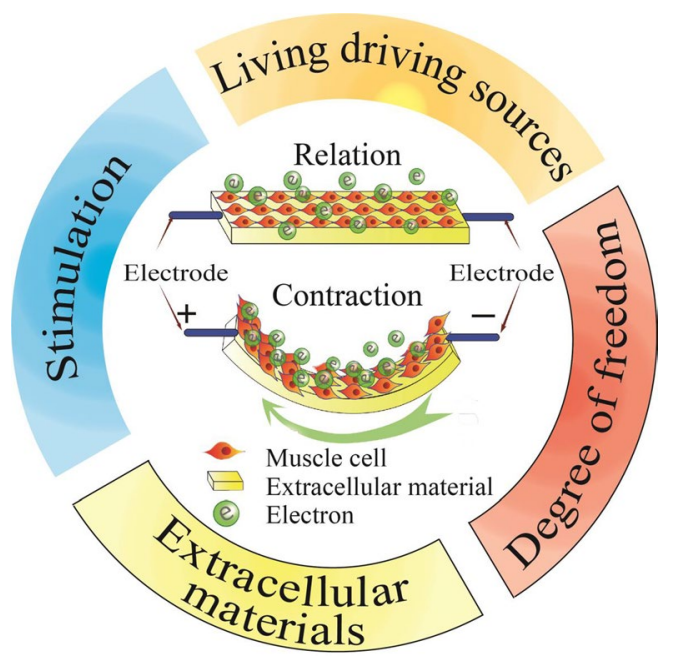

Keywords Biohybrid robots $\cdot$ Living cells $\cdot$ Actuator materials $\cdot$ Structure $\cdot$ Control methodologies

Tao Jiang

jiangtao@nudt.edu.cn

$\triangle$ Jianzhong Shang

jz_shang_nudt@163.com

Zening Lin

linzening@nudt.edu.cn
Department of Intelligent Machinery and Instrument, College of Intelligence Science and Technology, National University of Defense Technology, Changsha 410073, China 


\section{Introduction}

Robotic technology has been rapidly developing in the past few decades and has already benefited humans in numerous heavy and repetitive tasks. Despite the predominant focus on large-scale robots, recent years have also witnessed an increased interest in intelligent microrobots. Due to their small size, micro-robots can simulate the shape and movements of real organisms, allowing for operations that would be otherwise difficult to complete by traditional robots. For example, during earthquakes, micro-robots can move among ruins for search and rescue; or in medical treatments, they can enter the human veins for minimally invasive surgery.

A robot is mainly composed of drivers, control systems, executing mechanics, and sensors [1-3]. Among them, the driver as the power conversion component of the robot determines its motion patterns and performance. The key to the design and manufacture of micro-robots is the miniaturization of the drivers. Micro-robot drivers can be divided into three categories: traditional rigid drives [4-8], flexible material drives [9-13], and biomaterial drives [14-18].

Traditional rigid drives include hydraulic, pneumatic, and the most commonly used electromagnetic motor. For example, the cockroach-like robot developed by Najafi's group [19] and the fruit fly-like robot developed by Croon's group [20] use the motor to realize walking or flying motions. Although this traditional driving technology is supported by well-developed control theories and sophisticated manufacturing processes, its operating principle is quite different from that of the real organism resulting in its incapability to accurately simulate its motion characteristics. More importantly, when the size of the driver needs to be reduced to the millimeter-scale or smaller, the manufacturing difficulty of traditional drivers sharply increases, while their output force and power density decrease exponentially (millimeter scale, maximum output force about $10 \mu \mathrm{N}$, output power density $<0.01 \mathrm{~kW} / \mathrm{kg}$ ) [21, 22]. Meanwhile, its unsatisfying reliability, relatively short lifespan, low energy efficiency, and other defects at the miniature scale become deteriorated. For instance, the battery-powered fully charged beelike micro-robot developed by Harvard University can only fly for a few seconds [7]. The hummingbird robot driven by two motors developed by Purdue University can merely fly for $1.23 \mathrm{~min}$ at most [23].

Faced with the defects of conventional rigid drivers, new driving methods via using flexible stimuli-active materials such as dielectric elastomer actuator (DEA) [24-26], shape memory alloy (SMA) [27-29], and liquid crystal elastomer (LCE) [30-33] are developed. For example, Wood's [34] team developed a flying robot driven by multilayer dielectric elastomers, which can perceive and withstand collision with obstacles and recover from collisions by taking advantage of the robustness of the material and the passive stability of the machine. Compared with traditional driving methods, this flexible material drive can be powered by electrical stimulation at the millimeter or even smaller scale, and among other advantages, has better self-repair capability and reliability. However, due to the lack of in-depth research on stress, strain, response speed, efficiency, and lifespan, research on flexible material drivers is still in its infancy, and certain disadvantages, such as low power density and high driving voltage, are still hindering its practical applications.

In contrast, with the development of interdisciplinary subjects in bioengineering, nanotechnology, and threedimensional (3D) bioprinting [35-39], the combination of biological living actuators and nonliving biomaterials became a possible solution for overcoming the limitations of existing driving methods. Compared with the traditional rigid-driven and flexible material-driven robots, biomaterial-driven biohybrid robots (also known as biobots) can better recapitulate the microstructures and motion patterns of living organisms, with remarkable advantages of high controllability, output force, and power density at the millimeter and smaller scales, accompanied by the potential of self-assembly, self-repair, and self-replication capabilities [40-44]. For example, the micro-robot designed by Bashir et al. [45] can carry out accurate multidirectional and steering motion under the action of light stimulation, which shows high controllability and energy efficiency.

In nature, living creatures usually show high flexibility and energy conversion efficiency and thus may hopefully be the models of a new generation of robots. Biohybrid robots with unprecedented biomimicry in driving performance can potentially yield great applications in mechanics, biomedicine, material science, chemical engineering, and many other fields. This review aims to give a comprehensive review of the up-to-date developments of biohybrid robots. The present section provides an introduction to biohybrid robots. Next, an in-depth review of the related research on the driving technology of micro-biobots is presented. Considering biology, material science, machinery, and other relevant disciplines, we describe the biobots from three main aspects: biological composition, underlying materials, and structure/control mechanisms, while highlighting the latest progress of each field. Finally, we discuss and summarize the potential applications and future challenges of biohybrid robotics research. 


\section{Living driving sources used for biohybrid robots}

Most traditional rigid robots and soft material robots are unable to meet the requirements of miniaturization and energy efficiency at the same time. A new type of driving source with high flexibility and driving force is therefore urgently needed to satisfy the size and output force demands of robots [46-49]. Many naturally evolved living tissues can produce the necessary driving forces with durability, and they can potentially be used as ideal drivers for micro-biobots. Xi et al. [50] first proposed a biological robot in 2005, which opened a Pandora's box and triggered rapid developments in this field for the next 15 years. According to biological composition, biological driving sources can be roughly divided into five categories: mammalian primary cells [51-55], mammalian cell lines (mainly cardiomyocytes and skeletal muscle cells) [14, 56-59], insect dorsal vascular tissue (DV tissues) [60-63], microorganisms [64-68] and others (sperm, T cells, etc.) [69-73] (shown in Fig. 1 and Table 1). The latest developments of each category is reviewed in the following chapters.

\section{Mammalian cells}

Herein, the reference to primary mammalian cells generally means the cell suspension extracted from mammalian organs or muscles, which can form new muscle tissue after tissue culturing. The most commonly used cells of this type are primary cardiomyocytes and primary skeletal muscle cells extracted from newborn mice. The muscle actuators of these two types of cells have been widely used in biohybrid robots
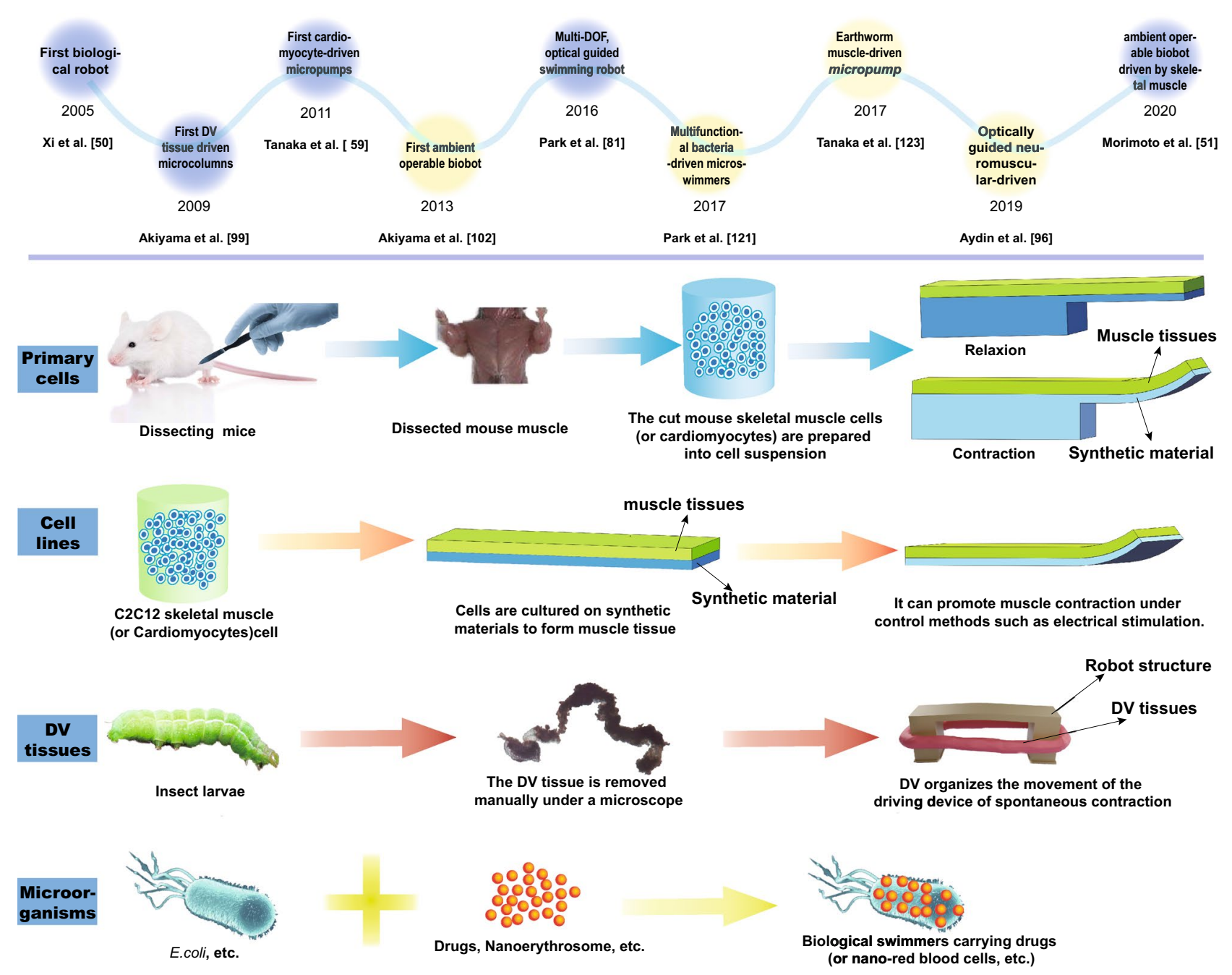

Fig. 1 The top of the figure shows some major milestones in biomaterial-driven bio-robot research from 2005 to 2020 . The overall design process of a biological robot made up of primary cells, cell lines, dorsal vascular (DV) tissue, and microorganisms is demonstrated at the bottom 
Table 1 Advantages and disadvantages of different sources of driver

\begin{tabular}{|c|c|c|}
\hline Driven source & Advantage & Disadvantage \\
\hline Primary cardiomyocytes & $\begin{array}{l}\text { Spontaneous and synchronous contraction; } \\
\text { Natural biocompatibility, high efficiency and } \\
\text { driving force }\end{array}$ & $\begin{array}{l}\text { The spontaneous contractions hinder precise control; } \\
\text { Relatively short lifespan and potential ethical problems }\end{array}$ \\
\hline Primary skeletal muscle cells & Controlled contraction & Relatively short lifespan and potential ethical problems \\
\hline Cardiomyocytes derived from stem cells & Circumvention of ethical problems & $\begin{array}{l}\text { Relatively lower driving force; } \\
\text { Increased procedures to induce stem cell differentiation }\end{array}$ \\
\hline C2C12 cells & $\begin{array}{l}\text { High controllability; } \\
\text { High shape/geometry design flexibility; } \\
\text { Ability to regenerate fibers after injury }\end{array}$ & $\begin{array}{l}\text { Limited biological relevance versus primary cells; } \\
\text { Demanding culture conditions versus DV tissue }\end{array}$ \\
\hline DV tissue & $\begin{array}{l}\text { Spontaneous contraction; } \\
\text { High survivability under harsh environments }\end{array}$ & $\begin{array}{l}\text { Lack of controllability; } \\
\text { Lack of well-developed culture protocols }\end{array}$ \\
\hline Microorganisms & $\begin{array}{l}\text { Smaller size (on the micrometer-scale); } \\
\text { High relative speed; } \\
\text { High survivability under harsh environments }\end{array}$ & $\begin{array}{l}\text { Limited immunogenicity; } \\
\text { Relatively lower output force }\end{array}$ \\
\hline
\end{tabular}

due to sufficient developmental plasticity, which allows them to be planted on extracellular materials to form integrated devices.

\section{Primary cardiomyocytes}

These cells are generally isolated from the ventricles of infant rats and then planted on artificial materials to form muscles. Primary cardiomyocytes feature spontaneous and synchronous contraction after being implanted onto artificial materials and cultured for 2 days, and generally reach stability after 6 days [74-76]. The approximate size of a single cardiomyocyte is $100 \mu \mathrm{m} \times 100 \mu \mathrm{m} \times 10 \mu \mathrm{m}$, and its rhythmic contraction can produce a force of about $10 \mu \mathrm{N}$ [77]. The maximum output force will further increase as muscle cells differentiate into muscle tissues, becoming larger than the driving force of traditional robots proportionally shrunk to the same microscale. As a result, cardiomyocytes are widely used to drive various biological robots to achieve deformation, walking, grasping, and other operations.

In 2005, for example, Xi et al. [50] developed the first walking robot with the ability to move autonomously (138 $\mu \mathrm{m}$ long and $40 \mu \mathrm{m}$ wide legs), and the study laid the foundations for follow-up developments. Driven by the spontaneous contraction of cardiomyocytes, the maximum speed of their robot can reach $38 \mu \mathrm{m} / \mathrm{s}$ after 3 days of culturing. Similarly, Bashir et al. [78, 79] presented a cardiomyocyte-driven mobile robot consisting of a "biological bimorph" cantilever structure and an asymmetrically shaped base, as shown in Fig. 2a. The optimal size of the cantilever beam was established as $7 \mathrm{~mm} \times 2 \mathrm{~mm} \times 182 \mu \mathrm{m}$. The contraction of cardiomyocytes causes the retention of the asymmetric structure and subsequently drives the robot to walk with a maximum speed of $236 \mu \mathrm{m} / \mathrm{s}$. In the same year, Parker's team [80] developed a more complex jellyfish robot by combining computer-aided design with physiological performance, as shown in Fig. 2b. The speed of muscle contraction and relaxation can be controlled by electrical stimulation, which can drive and control the jellyfish-shaped polydimethylsiloxane (PDMS) film to swim toward a specified direction.

Although cardiomyocytes can contract spontaneously, the ability to perform designed and controllable maneuvers is a more preferable asset of a biobot. Based on their previous research, Parker et al. designed a batfish robot in 2016 [81] (shown in Fig. 2c). The cardiomyocytes were modified by cell and genetic engineering and cultured on an elastomer wrapped in a miniature metal skeleton, such that they were distributed in a serpentine pattern. Through controlling the light position to stimulate the local contraction of cardiomyocytes, this batfish can swim at a speed topped at $3.2 \mathrm{~mm} / \mathrm{s}$. When the motion control is realized, it is desirable to observe the motion state of the robot directly through the naked eye, which triggers research on visually observable feedback robotics. Zhao's team developed a caterpillar-like robot in 2020 [53] (Fig. 2d) via the secondary polymerization of carbon nanotube hydrogel to form structural color-changeable hydrogel stimulated by cardiomyocyte contractions. The orderly arranged silica nanoparticles produce a photonic bandgap structure, which results in the vivid structural color of hydrogel [82-84]. The motion state of the robot can thus be observed directly via scanning the color spectrum for changes. Moreover, under the action of a weak magnetic field, the robot can simulate the crawling behavior of caterpillars and realize autonomous directional movement.

Although primary cardiomyocytes have the advantages of natural biocompatibility, high efficiency, and high driving force, their spontaneous contractions hinder the precise control of cells to achieve complex tasks. Moreover, their 


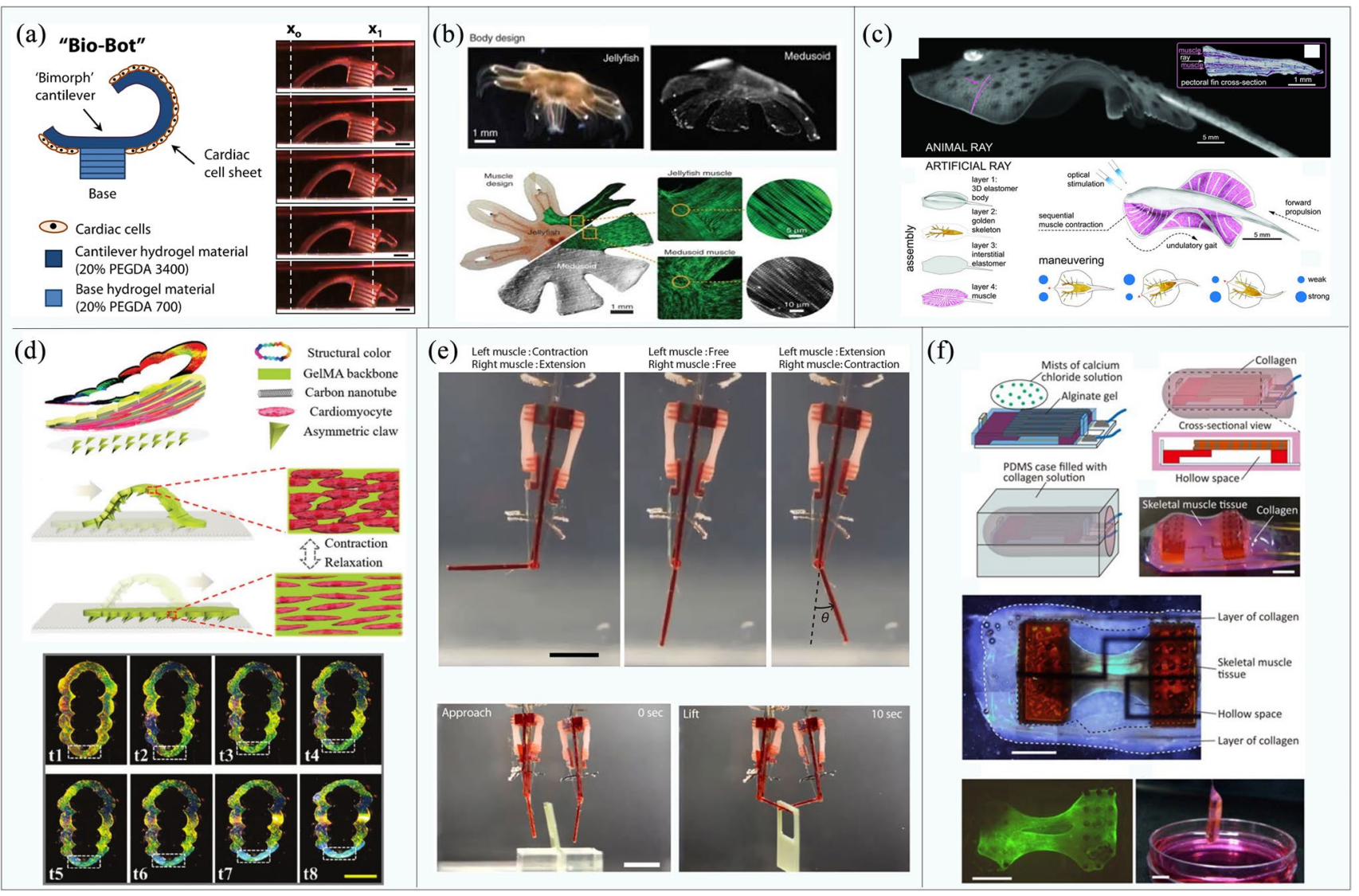

Fig. 2 Examples of biobots based on mammalian primary cells: a Biobots consisting of a biological bimorph cantilever with seeded cardiac cell sheets (reproduced with permission Ref. [79]); b jellyfish muscle architecture with customized functionalities contracted by properly aligned cardiomyocytes (reproduced with permission Ref. [80]); c a phototactic device driven by muscle tissue composed of cardiomyocytes (reproduced with permission Ref. [81]); d the crawl-

lifespan is relatively short with the output power gradually decreasing during one-week of culture [76].

\section{Primary skeletal muscles}

In comparison with the volume of research on primary cardiomyocytes, fewer studies exist on primary skeletal muscle cells. Despite their relatively short lifespan (several hours to a few days), primary skeletal muscle cells do not contract spontaneously, which allows for higher controllability and activities that are more dynamic and complicated [47].

In 2013, Morishima et al. [85] designed a living prosthesis driven by skeletal muscle. When the muscle is electrically stimulated, its "hand" is actuated to move. Despite its high controllability, skeletal muscle lacks consistency in the time dimension due to inherent internal traction during culturing. Given that, Takeuchi et al. [86] designed a biobot driven by a pair of antagonistic skeletal muscle tissue blocks to balance internal traction, as shown in Fig. 2e. ing process of the soft robot driven by cardiomyocytes and color variation during the movement process (reproduced with permission Ref. [53]); e a biobot powered by a pair of primary skeletal muscle tissues with biomimetic motion and its operation (reproduced with permission Ref. [86]); f construction of a biohybrid robot with the skeletal muscle tissue covered with a collagen structure (reproduced with permission Ref. [51])

Under $50 \mathrm{~Hz}$ electrical stimulation, the robot can achieve $90^{\circ}$ rotation movement by selectively actuating a specific muscle tissue, allowing the robot to grasp and place small objects. With the problem of intrinsic contraction solved, the lifespan of the robot can also be extended to over a week.

Although biobots driven by skeletal muscles can achieve all kinds of movements, the problem remains that they can only operate in culture medium instead of ambient air. In 2020, based on their previous research, Takeuchi's team developed a biobot capable of moving in the air [51], as shown in Fig. 2f. The robot wraps skeletal muscle tissue and flexible substrate material in a collagen structure to maintain the necessary humidity in the air. Results showed that the robot maintains high cell activity and contractility in the air and can bend under the action of electrical stimulation. Moreover, driving time can be greatly increased up to $1 \mathrm{~h}$ by using culture medium perfusion, which is four times longer than that without perfusion. 
Research on primary skeletal muscle-driven biobots has made great progress to date; however, challenges still exist in using primary cells because of their relatively short lifespan and potential ethical problems due to the associated animal sacrifice.

\section{C2C12 skeletal muscle cells}

Skeletal muscle cell lines (such as C2C12) are more popular in research than derived cardiomyocytes, as they offer ideal power sources for biobots that require full controllability and a modular design. Skeletal muscle is formed by parallel fiber bundles. Mechanical and electrical stimulation can promote cell differentiation into muscle [87-89], strengthen muscle functions, and drive the movements of biobots. In addition, the energy supply of skeletal muscle cells comes from adenosine triphosphate (ATP), which is more effective than conventional motor drives at the microscale. Therefore, extensive research has been carried out on numerous robots driven by skeleton muscle cell lines. For example, Bashir et al. [90] developed a biped beam robot with asymmetric structure through 3D printing for performance optimization, as shown in Fig. 3a. The biobot can reach a maximum unidirectional moving speed of $156 \mu \mathrm{m} / \mathrm{s}$ (the size of the robot is $6 \mathrm{~mm} \times 3 \mathrm{~mm} \times 1.2 \mathrm{~mm}$ ). The robot is also the first untethered biological robot driven by skeletal muscle that is fully controllable by external signals. However, it still has two limitations, in that (1) structural adaptiveness is limited due to fixation of muscle rings and (2) unidirectional moving pattern is a barrier of its maneuverability. The same group subsequently designed a quadruped robot driven by $\mathrm{C} 2 \mathrm{C} 12$ skeletal muscle cells modified by a photosensitive stimulator [45], as shown in Fig. 3b. Skeletal muscle cells differentiate into muscle rings, which can achieve a directional movement by local light stimulation on a single muscle ring. Also, the muscle rings can be manually transferred to a wide variety of biobot skeletons. On this basis, the team proposed a modular skeletal muscle design method [91]. The millimeter actuator

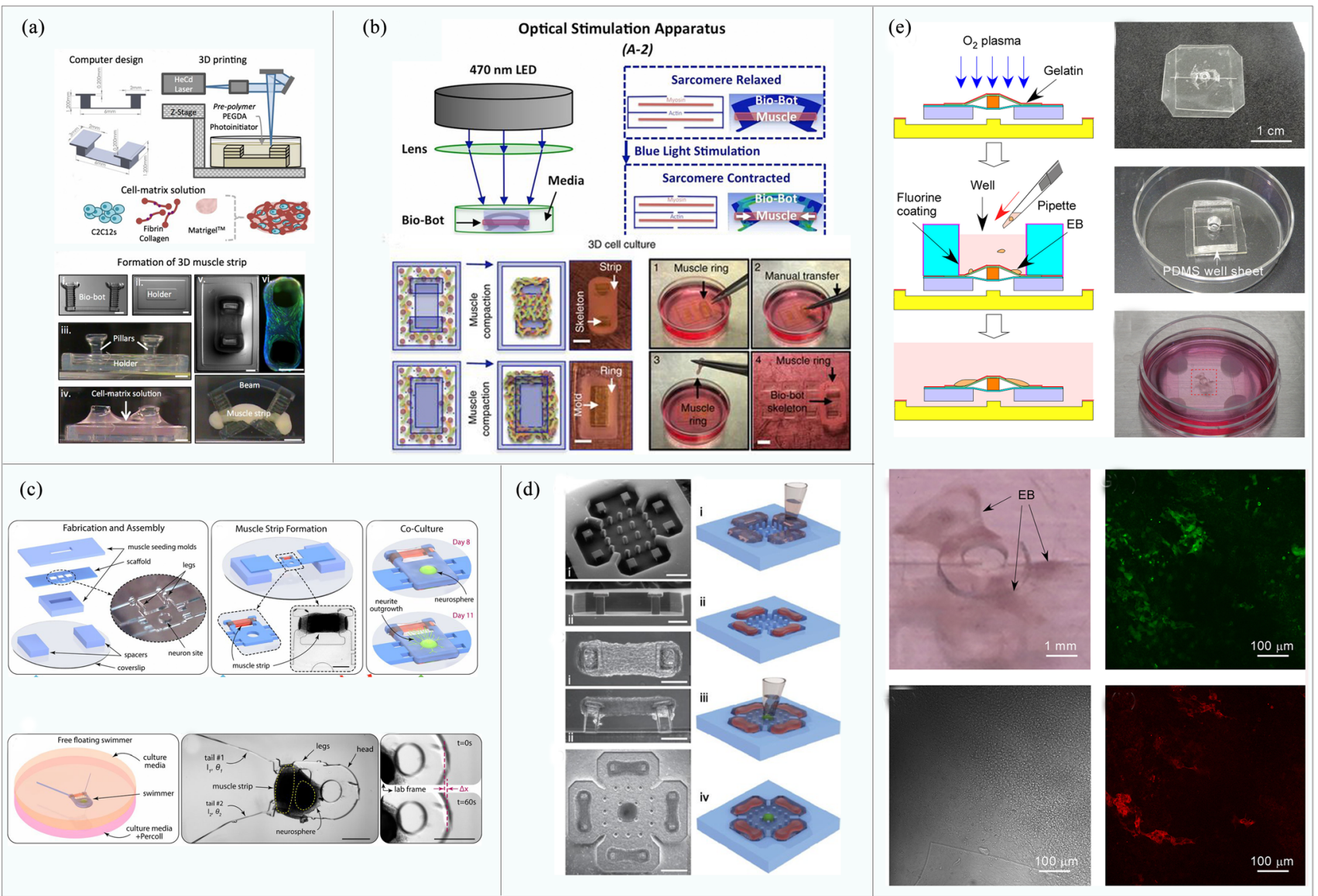

Fig. 3 Examples of biobots based on mammalian cell lines. a Bipedal robot driven by $\mathrm{C} 2 \mathrm{C} 12$ skeletal muscle and its manufacturing method (reproduced with permission Ref. [90]); b preparation of muscle ring for driving a robot (reproduced with permission Ref. [45]); c a modular approach to the design, fabrication, and characterization of mus- cle-powered biological machines (reproduced with permission Ref. [95]); d general coculture platform of neuron and muscle (reproduced with permission Ref. [96]); e a miniature pump powered by frozen cardiomyocytes (reproduced with permission Ref. [100]) 
can be used to actuate various 3D-printed skeletons (such as biped beam, quadruped beam, and even octopod robot), thus improving the versatility of the drive.

Electrical stimulation and light stimulation are common methods to control skeletal muscle, but their mechanisms are still different from that of real organisms. The movements of real organisms are achieved by the transmission of electrical signals through neural networks, which stimulate and drive the contraction and relaxation of muscle tissue, thereby coordinating the movements of specific body parts [92-94]. It was not until 2019 that a step toward this goal was demonstrated by Saif et al. [95] in the form of a double-tailed swimmer robot driven by nerves and muscles (shown in Fig. 3c). Therein, the muscle tissue formed by $\mathrm{C} 2 \mathrm{C} 12$ skeletal muscle cells was cocultured in situ with neurons, causing the selective extension of motoneuron axons to muscle tissue to form a functional neuromuscular unit. Upon light stimulation, the neuromuscular-driven robot can swim at a speed of $0.7 \mu \mathrm{m} / \mathrm{s}$ in liquids with a low Reynolds coefficient. On this basis, the team designed a general 3D neuromuscular coculture platform [96] (shown in Fig. 3d). The platform allows for coculturing neuron clusters with up to four target muscles and for quantifying the muscle contractile force. It also provides the means to further explore the role of synergy in the development of neuromuscular biological drivers.

Given the advancements of research in recent years, mammalian muscular cells, whether primary cells or cell lines, seem a highly promising driving source for biobots. However, they also have drawbacks such as a relatively short lifespan, dependence on culture conditions (nutrients, oxygen, temperature, $\mathrm{pH}$ ), and other in vivo conditions to properly function.

\section{Cardiomyocytes derived from stem cells}

Research on mammalian primary cell lines played a remarkable part in the development of transformed cell lines used for muscle tissue to drive biobots, which are discussed in this section.

Cardiomyocytes can be formed by inducing the differentiation of stem cells via chemical, electrical, or other stimulation methods [97]. Since the number of cardiomyocytes is normally constant in living organisms, cell lines of this type are generally difficult to obtain. Unlike primary cardiomyocytes that can be connected to cell slices to boost output force [59], separated cardiomyocytes can merely generate a limited force. Due to these reasons, attention is paid to optimizing the structural design of biobots driven by this cell type. For instance, Tanaka et al. [59] constructed micropumps from frozen rat cardiomyocytes, which collect the forces generated by cardiomyocytes through membranes and cubes, and transfer them to pump fluids. The theoretical flow rate of their micropump can reach $6.3 \mathrm{~nL} / \mathrm{min}$, which is consistent with that of the previous micropumps formed by primary cardiomyocytes $[98,99]$, proving the feasibility of microdevices driven by stem cell-derived cardiomyocytes. The same team further developed a new type of micropump drive system [100] (shown in Fig. 3e) by inducing the differentiation of mouse embryoid cells to form cardiomyocytes in situ. After two weeks of culture, a periodic oscillation of the pump can be observed, and the theoretical flow rate is 6.9 $\mathrm{nL} / \mathrm{min}$, which also reaches that of micropumps driven by primary cardiomyocytes. However, the complexity and cost of inducing stem cells to differentiate into cardiomyocytes are existing challenges, and it is crucial to have an optimized control of culture conditions for practical application.

\section{Insect dorsal vessel (DV) tissue}

The central pulsating blood vessel on the back of insects plays the role of the heart, which contracts at a constant frequency without any stimulation. It contains DV tissue that, as another actuation source, shows many distinctive properties that surpass its mammalian counterparts. For example, insect tissues can survive under a wider range of external and internal environmental conditions, such as a temperature range of $0-55^{\circ} \mathrm{C}$ and a $\mathrm{pH}$ range of $4-11$. Some insect tissue can even survive complete hypoxia for several days [101]. In terms of lifespan, robots driven by insect DV tissue can live for up to 90 days without the need for medium change, which is much longer than that of biobots driven by mammalian cells [102].

Morishima et al. [103] developed an insect musclepowered autonomous micro-robot, the maximum speed of which can reach $257 \mu \mathrm{m} / \mathrm{s}$, which is faster than that of previously reported biobots $[50,104]$. In the footsteps of that project, they developed a biological driver that can operate in the ambient environment, and consists of DV tissue, micro-tweezers, and capsules [105] (shown in Fig. 4a). The self-shrinking driving tweezers can be turned on and off by transferring the actuator from the medium to the air. Moreover, the service life can be extended from about 40 min to 5.2 days by pouring liquid paraffin on the surface of the capsule. This study shows the great potential of insect DV tissues as biological drivers operable under ambient environment.

In 2019, Morishima et al. proposed a swimmer prototype driven by DV tissue [62] (shown in Fig. 4b) that reaches an average swimming speed of $11.7 \mu \mathrm{m} / \mathrm{s}$. Although the robot is slower than some other swimming robots [106], the provided driver solution is a low-cost, biomimetic, and conveniently available option.

Insect-derived drivers provide alternatives to biological actuators and are of particular interest in robotic applications for harsh environments. 


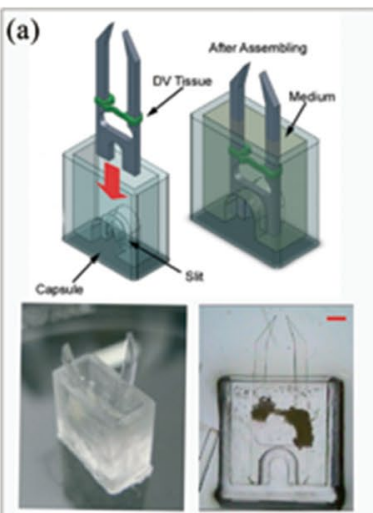

(d)

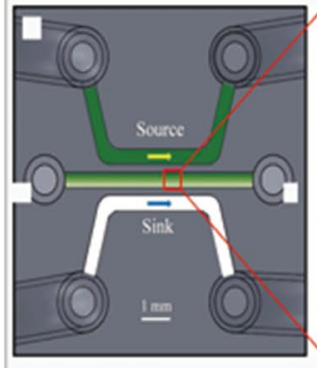

(b)

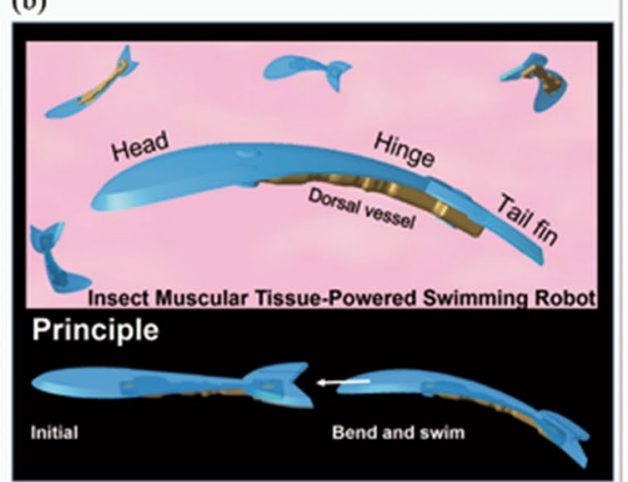

(e)
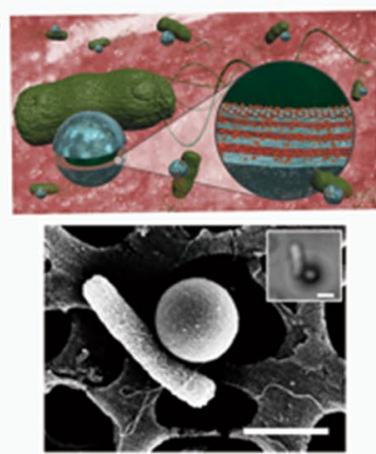

(c)
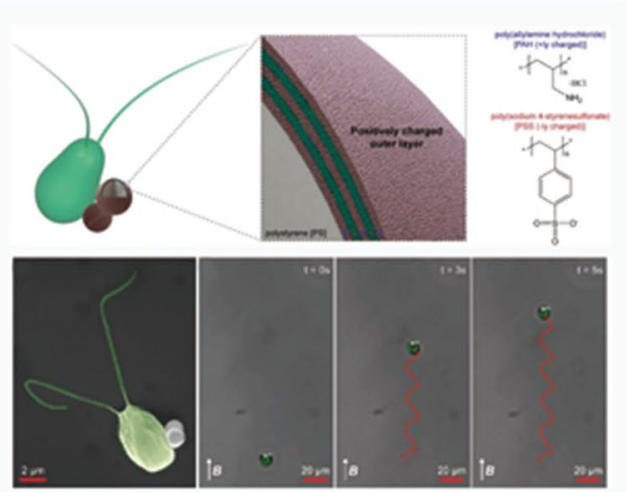

(f)
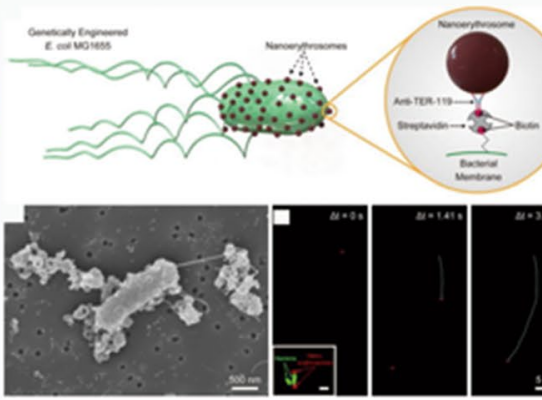

Fig. 4 Examples of biobots based on DV tissues and microorganisms. a The schematic design and actual digital images of the biohybrid tweezer power by packaging insect DV tissue in culture medium to expand the application range (reproduced with permission Ref. [105]); b an autonomous swimming biobot driven by autonomous pulsation of DV organization (reproduced with permission Ref. [62]); c a biocompatible biohybrid microswimmer powered by a unicellular freshwater green microalga (reproduced with permission Ref. [121]);

\section{Microorganisms}

In addition to biobots driven by muscle cells, microorganisms are also widely used to actuate biobots [107-111]. Microorganisms have the advantages of small size, low weight, high speed, and high viability [112, 113]. Furthermore, they have the ability to show magnetotaxis, chemotaxis, and responses to other physio-chemical stimuli. Microbial robots can mainly be divided into those driven by microalgae [114, 115] and bacteria [116-119].

With respect to microalgae, Liu et al. [120] developed a method to control microswimmers based on phototaxis. Under the guidance of $490 \mathrm{~nm}$ light-emitting diode (LED) light, microswimmers can be controlled to swim back and forth, and successfully realize the movements along zigzag, triangle, and other arbitrarily set trajectories, showing great significance for transporting drugs in the field of biomedicine. In 2018, Sitti et al. built a biobot based on the interaction between a negatively charged Chlamydomonas reinhardtii [121] and positively charged polyelectrolyte d biohybrid bacteria-driven microswimmers and a three-channel microfluidic concentration gradient generator (reproduced with permission Ref. [124]); e a multifunctional microswimmer consisting of a single Escherichia coli attached to the surface of drug-loaded polyelectrolyte multilayer particles embedded with magnetic nanoparticles (reproduced with permission Ref. [125]); f a biobot with immunogenicity formed by the interaction between nano-red blood cells and Escherichia coli (reproduced with permission Ref. [126])

(PE) functionalized magnetic polystyrene (PS) particles, as shown in Fig. 4c. Under the implementation of a $26 \mathrm{mT}$ uniform magnetic field, the average speed of the microswimmers reaches about $150 \mu \mathrm{m} / \mathrm{s}$, which is much faster than that of most other microswimmers [122, 123]. Moreover, their microorganism-based robot shows good cytocompatibility, steady performance and survivability under physiological conditions and can be manufactured by relatively simple procedures.

Compared with microalgae, bacteria-driven robots have been more commonly studied and developed. For example, Sitti et al. [124] first elucidated the basic physical mechanisms of a seemingly synergistic chemotaxis between multiple bacteria attached to the same microstructure by studying a biological hybrid microswimmer system driven by multiple Serratia marcescens cells, as shown in Fig. 4d. Results showed that the heading deviation of microswimmers is the main factor leading to chemotactic drift. On this basis, they developed a high-performance multifunctional microswimmer in 2017 [125], which features a single E. coli 
cell attached to the surface of drug-loaded polyelectrolyte multilayer (PEM) particles embedded with magnetic nanoparticles, as shown in Fig. 4e. Biased and directional motion can be realized under the gradient of the magnetic field and chemical attractants, and the drift velocity under chemical stimulation $(2.0 \mu \mathrm{m} / \mathrm{s})$ is higher than that achieved in previous studies $(0.66 \mu \mathrm{m} / \mathrm{s})$.

Although bacteria-driven swimming robots have great potential, especially in biomedical drug transport, their immunogenicity and low motor performance still pose great challenges. A forward step was made by Sitti's team, who developed a robot formed by the interaction between $E$. coli and nano-red blood cells [126], as shown in Fig. 4f. The robot not only has no immunogenicity, but also higher speed performance $(14.06 \pm 6.71 \mu \mathrm{m} / \mathrm{s})$ than other robots driven by $E$. coli, thus providing a reference for follow-up research.

\section{Other biological components}

In addition to common mammalian muscle cells and DV tissues, many other biomaterials have been studied as driving sources for biological robots, such as sperm cells, macrophages, non-mammalian cardiomyocytes, or muscle tissues of Drosophila larvae. For example, Tanaka et al. [127] developed a new type of micropump (size is $2 \mathrm{~cm} \times 2 \mathrm{~cm}$ ) made of natural earthworm muscle and PDMS microchip (shown in Fig. 5a). Upon the application of electrical stimulation, the muscle tissue generates a maximum force of $9.33 \mathrm{mN}$. Meanwhile, the flow rate can reach $5.0 \mu \mathrm{L} / \mathrm{min}$, which is 3-4 magnitudes higher than that of a previously reported cardiomyocyte pump and comparable to those of the traditional pump [128-130]. Morishima et al. used similar methods to develop a micro-peristaltic pump from

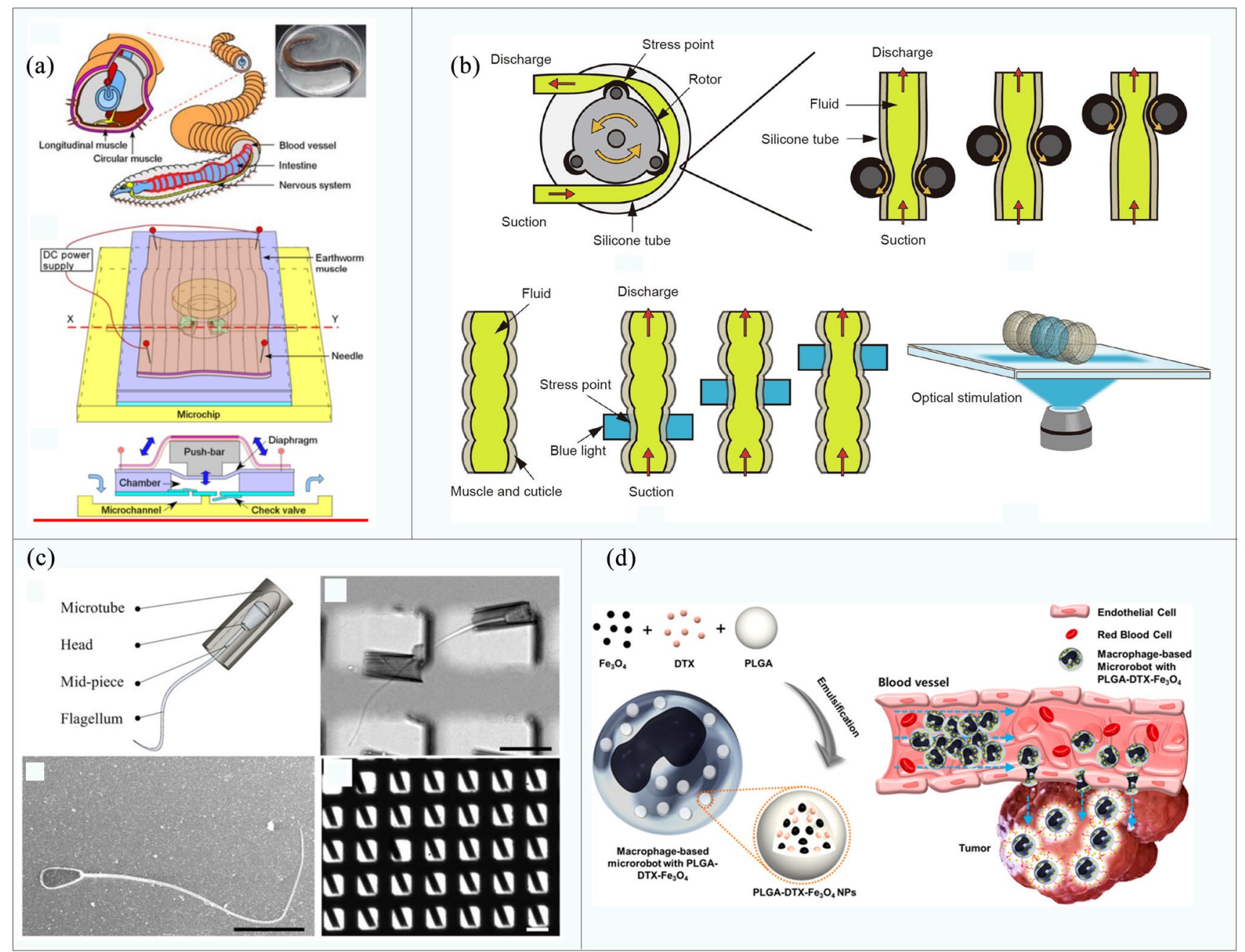

Fig. 5 Examples of biobots based on other biological components. a Micropump prepared from earthworm muscle tissue (reproduced with permission Ref. [127]); b light-responsive muscles obtained from Drosophila larvae are made into micro-creeping tubes that can transport microbeads (reproduced with permission Ref. [55]); c spermbots consisting of single sperm cells captured in artificial magnetic microstructures (reproduced with permission Ref. [131]); d a method of manufacturing a biological robot composed of macrophages (reproduced with permission Ref. [133]) 
the light-responsive muscle obtained by $\mathrm{ChR} 2$ genetically engineered fruit fly larvae [55], as shown in Fig. 5b. Under the stimulation of blue light, it can transport beads at a speed of $120 \mu \mathrm{m} / \mathrm{s}$.

In addition to the muscle tissue obtained from animals such as larvae, sperm is also a biomaterial that has attracted attention because of its extraordinary motion performance. Khalil et al. [131] studied the hydrodynamic effects of a sperm robot composed of bull sperm cells and microtubules (shown in Fig. 5c) in a heterogeneous viscous medium similar to the in vivo environment. It was revealed that the driving force of the sperm robot can be increased by shortening the microtubule size and increasing the magnetic moment. Based on this result, they compared the driving characteristics of active sperm cells with magnetically driven dead sperm cells [132], which provided an insight into the structural design of microswimmers. Furthermore, Park's team developed a macrophage micro-robot [133] (shown in Fig. 5d) that consists of phagocytosis of iron oxide $\left(\mathrm{Fe}_{3} \mathrm{O}_{4}\right)$ nanoparticles and poly(lactic-co-glycolic-acid) (PLGA) nanoparticles encapsulated by docetaxel (DTX) in a mousederived macrophage line. Driven by the electromagnetic actuation (EMA) system, the robot can target tumor cells and show a potential in targeted therapies.

\section{Extracellular materials for biohybrid robots}

A further important component of biohybrid robots is the substrate material [134-137]. Since the substrate provides structural support and the environment for cell growth, it needs to have desirable flexibility and biocompatibility. Cells are either attached to or embedded in the substrate material. Based on the nature of material, commonly used substrate materials can be categorized into three types: bioinert polymers [52, 138-140], hydrogels (including bioactive hydrogels [134, 135, 141-144] and artificial hydrogels [145, 146], and tissue harvested biomaterials (such as decellularized extracellular matrix) [17, 147-149], as shown in Tables 2 and 3. In this section, we describe the latest progress of biohybrid robot developments based on these three types of substrate materials.

\section{Bioinert polymer}

The most commonly used base material among bioinert polymers is the PDMS elastomer due to its tunable stiffness and numerous possible manufacturing methods (shown in Table 1). However, it has limited bio-motifs for cells to attach to; therefore, it is imperative to improve its bioactivity by appropriate molecules [150]. Structures of PDMS are generally fabricated by die casting [52,151], surface coating [76, 81], film cutting [80, 152], and 3D bioprinting [139].

Holley et al. [76] developed a "fin"-driven swimming robot, which consists of a substrate made of two composite bioinert polymers and a PDMS cantilever with a cardiomyocyte fusion layer, as shown in Fig. 6a. The diving depth, pitch, and rolling of the robot can be maintained without external intervention. Moreover, its maximum speed and deflection displacement reach $142 \mu \mathrm{m} / \mathrm{s}$ and $2.5 \mathrm{~mm}$ (driver length $4 \mathrm{~mm}$ ), respectively. The robot can maintain high stability via the proper configuration of the substrate mass density. Using the same type of material, Guria et al. [153] designed a biologically driven micropump by planting cardiomyocytes on a PDMS film coated with fibrinogen (FN). The pump generates flow through the peristaltic movement of its wall actuated by the directional controlled contraction/ extension of cardiomyocytes. Tanaka et al. [52] poured neonatal rat cardiomyocyte suspension onto PDMS micro-molds and cultured them for 7 days. The resulting myocardial tissue bridged the PDMS micro-bridge piers to make the smallest ultra-miniature fluid oscillator ever made for water pumping $(200 \mu \mathrm{m} \times 200 \mu \mathrm{m} \times 150 \mu \mathrm{m})$, as shown in Fig. $6 \mathrm{~b}$. The cardiomyocytes could output approximately $14.6 \mu \mathrm{N}$ of peak force by spontaneous contraction, and the simulated flow pattern and velocity distribution were in good agreement with the experimental results.

As opposed to a PDMS elastomer, Fujie et al. [57] cultured $\mathrm{C} 2 \mathrm{C} 12$ skeletal muscle cells on a styrene-blockbutadiene-block-styrene (SBS) microgroove membrane. Cells differentiated and developed into muscle tissue,
Table 2 Performance comparison of different base materials

\begin{tabular}{|c|c|c|c|c|}
\hline & \multirow[t]{2}{*}{ Bioinert polymer } & \multicolumn{2}{|l|}{ Hydrogels } & \multirow{2}{*}{$\begin{array}{l}\text { Tissue } \\
\text { harvested } \\
\text { biomaterials }\end{array}$} \\
\hline & & $\begin{array}{l}\text { Bioactive } \\
\text { hydrogel }\end{array}$ & $\begin{array}{l}\text { Artificial } \\
\text { hydrogel }\end{array}$ & \\
\hline Biological relevance & $*$ & $* * *$ & $* *$ & $* * * *$ \\
\hline Availability & $* * * *$ & $* *$ & $* * *$ & $*$ \\
\hline Cost & $*$ & $* * *$ & $*$ & $* * * *$ \\
\hline Mechanical tunability & $* * * *$ & $* * *$ & $* * * *$ & $* *$ \\
\hline Batch-to-batch consistency & $* * * *$ & $* *$ & $* * *$ & $*$ \\
\hline
\end{tabular}

Rank from high to low: ****, ***, **, * 
Table 3 Classification of synthetic materials for biological robots

\begin{tabular}{|c|c|c|c|c|c|c|c|}
\hline $\begin{array}{l}\text { Type of synthetic } \\
\text { material }\end{array}$ & Year & Synthetic material & Driving source & Control method & Locomotion & Degree of freedom & References \\
\hline \multirow[t]{13}{*}{ Bioinert polymer } & 2006 & \multirow[t]{12}{*}{ PDMS } & $\begin{array}{l}\text { Primary cardio- } \\
\text { myocytes }\end{array}$ & - & Pumping & Single-DOF & [98] \\
\hline & 2007 & & $\begin{array}{l}\text { Primary cardio- } \\
\text { myocytes }\end{array}$ & - & Pumping & Single-DOF & [161] \\
\hline & 2008 & & $\begin{array}{l}\text { Primary smooth } \\
\text { muscle }\end{array}$ & Chemical control & Bending & Single-DOF & [162] \\
\hline & 2009 & & DV tissue & - & Deflection & Single-DOF & [61] \\
\hline & 2011 & & Cardiomyocytes & - & Pumping & Single-DOF & [59] \\
\hline & 2012 & & $\begin{array}{l}\text { Primary cardio- } \\
\text { myocytes }\end{array}$ & Electric control & Swimming & Single-DOF & [80] \\
\hline & 2013 & & DV tissue & - & Gripping & Single-DOF & [105] \\
\hline & 2014 & & $\begin{array}{l}\text { Primary cardio- } \\
\text { myocytes }\end{array}$ & - & Swimming & Single-DOF & [163] \\
\hline & 2015 & & Cardiomyocytes & - & Pumping & Single-DOF & [100] \\
\hline & 2016 & & $\begin{array}{l}\text { Primary cardio- } \\
\text { myocytes }\end{array}$ & - & Swimming, rolling & Single-DOF & [76] \\
\hline & 2017 & & Cardiomyocytes & - & Pumping & Single-DOF & [139] \\
\hline & 2019 & & $\begin{array}{l}\text { Primary cardio- } \\
\text { myocytes }\end{array}$ & - & Pumping, bending & Single-DOF & [52] \\
\hline & 2019 & SBS & $\begin{array}{l}\mathrm{C} 2 \mathrm{C} 12 \text { skeletal } \\
\text { muscle }\end{array}$ & Electric control & Bending & Single-DOF & [57] \\
\hline \multirow[t]{10}{*}{ Bioactive hydrogel } & 2013 & \multirow[t]{5}{*}{ CNT-GelMA } & $\begin{array}{l}\text { Primary cardio- } \\
\text { myocytes }\end{array}$ & - & $\begin{array}{l}\text { Pumping, swim- } \\
\text { ming }\end{array}$ & Single-DOF & [158] \\
\hline & 2015 & & $\begin{array}{l}\text { Primary cardio- } \\
\text { myocytes }\end{array}$ & Electric control & Bending & Single-DOF & [164] \\
\hline & 2018 & & $\begin{array}{l}\text { Primary cardio- } \\
\text { myocytes }\end{array}$ & Electric control & Swimming & Single-DOF & [165] \\
\hline & 2019 & & $\begin{array}{l}\text { Primary cardio- } \\
\text { myocytes }\end{array}$ & - & Bending & Single-DOF & [74] \\
\hline & 2020 & & $\begin{array}{l}\text { Primary cardio- } \\
\text { myocytes }\end{array}$ & Chemical control & Walking & Single-DOF & [53] \\
\hline & 2014 & Gelatin & $\begin{array}{l}\text { Primary cardio- } \\
\text { myocytes }\end{array}$ & - & Bending & Single-DOF & [166] \\
\hline & 2016 & \multirow[t]{2}{*}{ FN } & $\begin{array}{l}\text { Primary cardio- } \\
\text { myocytes }\end{array}$ & Optical control & Swimming & Multi-DOF & [81] \\
\hline & 2019 & & $\begin{array}{l}\text { Primary cardio- } \\
\text { myocytes }\end{array}$ & Optical control & Swimming & Single-DOF & [54] \\
\hline & 2018 & \multirow[t]{2}{*}{ GelMA } & $\begin{array}{l}\text { Primary cardio- } \\
\text { myocytes }\end{array}$ & Chemical control & Bending & Single-DOF & [167] \\
\hline & 2019 & & $\begin{array}{l}\text { Primary cardio- } \\
\text { myocytes }\end{array}$ & - & $\begin{array}{l}\text { Swimming, bend- } \\
\text { ing }\end{array}$ & Single-DOF & [75] \\
\hline \multirow[t]{4}{*}{ Artificial hydrogel } & 2012 & $\begin{array}{l}\text { PEGDA, PEG- } \\
\text { collagen }\end{array}$ & $\begin{array}{l}\text { Primary cardio- } \\
\text { myocytes }\end{array}$ & - & Walking & Single-DOF & [78] \\
\hline & 2015 & PEG & $\begin{array}{l}\text { Primary cardio- } \\
\text { myocytes }\end{array}$ & - & Bending & Single-DOF & [159] \\
\hline & 2016 & PEDOT/MWCNT & $\begin{array}{l}\mathrm{C} 2 \mathrm{C} 12 \text { skeletal } \\
\text { muscle }\end{array}$ & Electric control & Bending, walking & Single-DOF & [92] \\
\hline & 2016 & PVDF, fibronectin & $\begin{array}{l}\text { Primary cardio- } \\
\text { myocytes }\end{array}$ & - & Bending & Single-DOF & {$[160]$} \\
\hline \multirow[t]{2}{*}{$\begin{array}{l}\text { Tissue harvested } \\
\text { biomaterials }\end{array}$} & 2011 & \multirow[t]{2}{*}{$\begin{array}{c}\text { Collagen I, } \\
\text { Matrigel }\end{array}$} & $\begin{array}{l}\text { Primary skeletal } \\
\text { muscle }\end{array}$ & Electric control & Bending & Single-DOF & [168] \\
\hline & 2012 & & $\begin{array}{l}\text { Transformation of } \\
\mathrm{C} 2 \mathrm{C} 12\end{array}$ & Optical control & Walking & Multi-DOF & [169] \\
\hline
\end{tabular}


Table 3 (continued)

\begin{tabular}{|c|c|c|c|c|c|c|c|}
\hline $\begin{array}{l}\text { Type of synthetic } \\
\text { material }\end{array}$ & Year & Synthetic material & Driving source & Control method & Locomotion & Degree of freedom & References \\
\hline & 2013 & & $\begin{array}{l}\text { Primary skeletal } \\
\text { muscle }\end{array}$ & Optical control & Gripping & Single-DOF & [85] \\
\hline & 2019 & & $\begin{array}{l}\text { Transformation of } \\
\text { C2C12 }\end{array}$ & Optical control & Swimming & Single-DOF & [95] \\
\hline & 2014 & Matrigel & $\begin{array}{l}\mathrm{C} 2 \mathrm{C} 12 \text { skeletal } \\
\text { muscle }\end{array}$ & Electric control & Walking & Single-DOF & [90] \\
\hline & 2018 & & $\begin{array}{l}\text { Primary skeletal } \\
\text { muscle }\end{array}$ & Electric control & Gripping & Double-DOF & [86] \\
\hline & 2019 & & $\begin{array}{l}\text { Primary skeletal } \\
\text { muscle }\end{array}$ & Electric control & Bending & Double-DOF & {$[147]$} \\
\hline & 2020 & & $\begin{array}{l}\text { Primary skeletal } \\
\text { muscle }\end{array}$ & Electric control & Walking & Single-DOF & {$[51]$} \\
\hline & 2015 & ELAC & $\begin{array}{l}\text { Primary cardio- } \\
\text { myocytes }\end{array}$ & Electric control & Swimming & Single-DOF & {$[170]$} \\
\hline & 2016 & $\begin{array}{l}\text { Matrigel, thrombin, } \\
\text { FN }\end{array}$ & $\begin{array}{l}\text { Transformation of } \\
\text { C2C12 }\end{array}$ & Optical control & Walking & Double-DOF & {$[45]$} \\
\hline & 2017 & & $\begin{array}{l}\mathrm{C} 2 \mathrm{C} 12 \text { skeletal } \\
\text { muscle }\end{array}$ & Electric control & Bending & Single-DOF & [149] \\
\hline & 2017 & & $\begin{array}{l}\text { Transformation of } \\
\text { C2C12 }\end{array}$ & Chemical control & Bending & Single-DOF & {$[148]$} \\
\hline & 2018 & & $\begin{array}{l}\mathrm{C} 2 \mathrm{C} 12 \text { skeletal } \\
\text { muscle }\end{array}$ & Electric control & Walking & Single-DOF & {$[171]$} \\
\hline & 2020 & & $\begin{array}{l}\mathrm{C} 2 \mathrm{C} 12 \text { skeletal } \\
\text { muscle }\end{array}$ & Electric control & Walking & Single-DOF & {$[172]$} \\
\hline \multirow[t]{7}{*}{ Others } & 2005 & $\mathrm{Cr} / \mathrm{Au}$ & $\begin{array}{l}\text { Primary cardio- } \\
\text { myocytes }\end{array}$ & - & Walking & Single-DOF & {$[50]$} \\
\hline & 2013 & Titanium and iron & Sperm & Magnetic control & Swimming & Single-DOF & [71] \\
\hline & 2013 & PS & Bacteria & Chemical control & Swimming & Single-DOF & [111] \\
\hline & 2016 & $\mathrm{Fe}_{3} \mathrm{O}_{4}$ & Macrophages & Magnetic control & Swimming & Single-DOF & [133] \\
\hline & 2016 & PS & Bacteria & Chemical control & Swimming & Single-DOF & [124] \\
\hline & 2017 & PDA & Bacteria & Magnetic control & Swimming & Single-DOF & [123] \\
\hline & 2018 & RBCs & Bacteria & Magnetic control & Swimming & Single-DOF & [173] \\
\hline
\end{tabular}

PDMS polydimethylsiloxane, $S B S$ styrene-block-butadiene-block-styrene, $C N T$-GelMA carbon nanotubes-methacrylated gelatin, $F N$ fibrinogen, $P E G D A$ poly(ethylene glycol) diacrylate, $P E G$ poly(ethylene glycol), $P V D F$ poly(vinylidene fluoride), $P E D O T$ poly(3,4-ethylenedioxythiophene), $M W C N T$ multiwalled carbon nanotubes, $E L A C$ electrochemically compacted and aligned collagen, $D V$ dorsal vessel, $P S$ polystyrene, $R B C s$ red blood cells, $P D A$ polydopamine

thus forming a biological hybrid driver with a membrane (shown in Fig. 6c). The film was optimized to a thickness of $2.5 \mu \mathrm{m}$ and Young's modulus of $55.2 \mathrm{MPa}$, which provides the maximum output via myotube contraction. Under the action of a $1 \mathrm{~Hz}$ electrical stimulation $(40 \mathrm{~V}$, $20 \mathrm{~ms}$ pulse width), the maximum displacement of the thin film $(10 \mu \mathrm{m} \times 3 \mu \mathrm{m} \times 2.5 \mu \mathrm{m})$ is $276 \pm 55 \mu \mathrm{m}$. The results are asymptotically compatible with those of finite element simulation. This study lays the foundations for the prediction of the shrinkage performance of the elastic film, with particular emphasis on the potential of microgroove SBS film as a super-flexible platform for biological hybrid machines.

\section{Hydrogel}

In addition to bioinert polymers, biocompatible hydrogels are commonly used as base materials for biobots. The rapid developments of hydrogel-based 3D bioprinting has greatly eased the design and fabrication process in studies involving biological models. Furthermore, mechanical properties can be tuned by controlling the molecular structure of the polymers and cross-linking agents to recapitulate those of natural tissues [154-156]. The microstructures of hydrogels allow the exchange of nutrients and gases, which is essential for cell survival, proliferation, and differentiation [157]; therefore, given their advantages over bioinert polymers, much research has been actively exploring the applications of hydrogels in bio-robotic fields. The hydrogels used for 
(a)

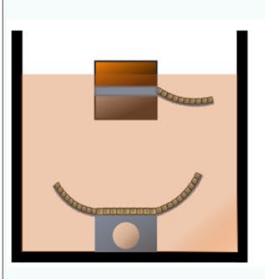

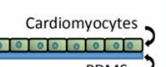
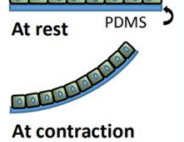

At contraction
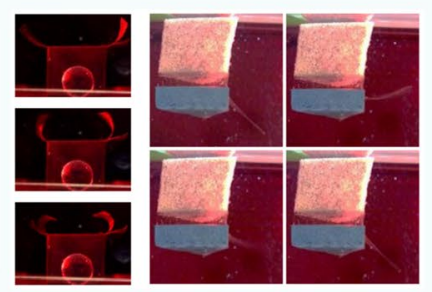

(b)
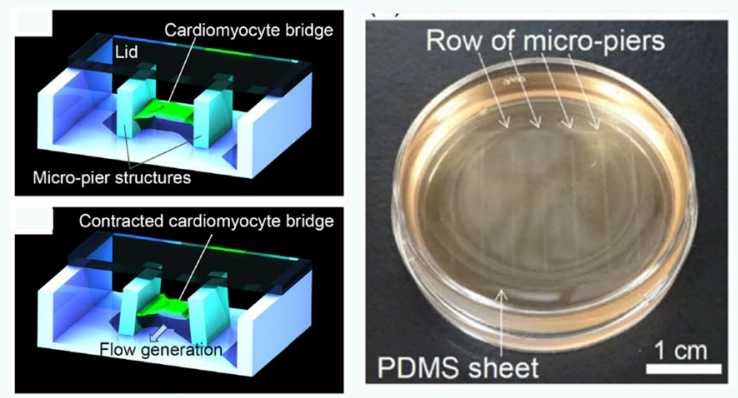

(c)

Biohybrid Actuators Consisting of Elastomeric, Microgrooved Thin Films

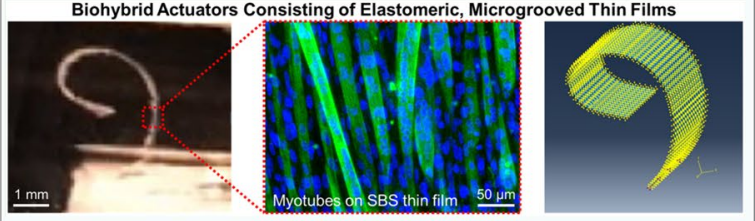

(d)
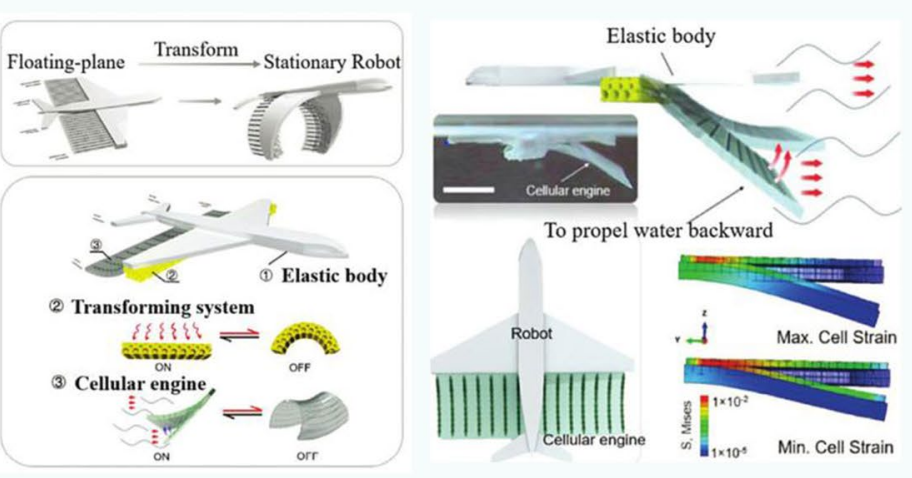

(f)

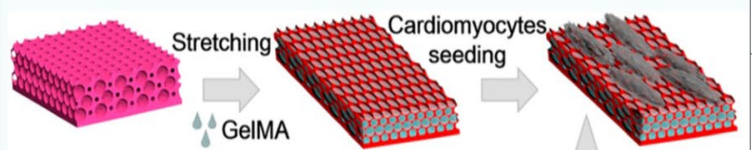

Relaxation

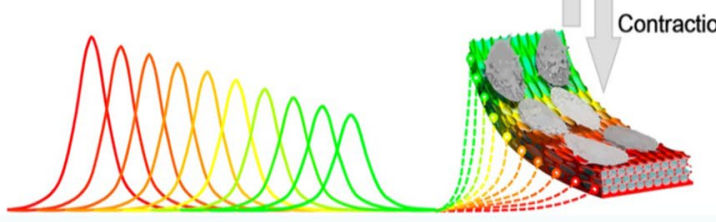

Fig. 6 Examples of biobots based on bioinert polymers and active hydrogels. a Swimming robot based on cardiomyocytes and PDMS (reproduced with permission Ref. [76]); b an actual ultra-miniature fluid oscillator for water pumping made by bridging PDMS micro bridge piers with myocardial tissue (reproduced with permission Ref. [52]); $\mathbf{c}$ a biological hybridization device formed by culturing $\mathrm{C} 2 \mathrm{C} 12$ skeletal muscle cells on the SBS microgroove membrane (reproduced with permission Ref. [57]); d the cardiomyocytes are added to the

biobots are mainly biologically sourced bioactive hydrogels and artificial biocompatible hydrogels.

\section{Bioactive hydrogels}

Biologically active hydrogels such as fibrinogen and gelatin derivatives usually originate from living organisms (animals or plants), and can therefore provide many biological properties of natural extracellular matrices, yet with significantly higher availability, such that they have been widely used for biobot fabrication. Shi et al. [54] added cardiomyocytes to a micropattern composed of fibrinogen for growth and differentiation to form muscle, and the swimming robot is formed with a flexible support and conversion system (reproduced with permission Ref. [54]); $\mathbf{e}$ a biological driver consisting of cardiomyocytes cultured in GelMA hydrogel (reproduced with permission Ref. [75]); f a cellular mechanical visual biosensor developed from GelMA hydrogel and morphobutterfly wings modified by carbon nanotubes (reproduced with permission Ref. [74])

micropatterned fibrinogen sheet for differentiation to form muscle tissue, which is combined with flexible supports and a conversion system to make a swimming robot, as shown in Fig. 6d. Through infrared light stimulation, the robot can change between the expanded and contracted state in a few seconds. Meanwhile, because the robotic system purposefully alleviates defects such as electrolysis, it can survive for up to three weeks, which is the longest lifespan of all drivers that have been hybridized with mammalian cells so far. Zhao et al. [75] cultured cardiomyocytes on GelMA hydrogel and anisotropically inversed opal matrix with oval macropores, 
resulting in a new biological driver shown in Fig. 6e. The anisotropic surface morphology of the hydrogel induces a highly directional ordered layout of the seeded cardiomyocytes and enhances the spontaneous beating capabilities of the muscle on the elastic matrix. The driver can produce color changes by periodic contraction and achieve visual feedback functions, which allows for the real-time observation of the driver's working status.

In order to further enhance the driving force of muscles, attempts have been made to combine carbon nanotubes with hydrogels for the improvement of electrical conductivity. Unidirectionally seeded carbon nanotubes can effectively induce the directional arrangement of cardiomyocytes and subsequently improve the driving force in a specific direction [53, 158]. In 2019, Zhao et al. developed a cellular mechanical visual biosensor [74] by combining GelMA encapsulated cardiomyocytes with carbon nanotubes coated morpho-butterfly wings (shown in Fig. 6f). The periodic self-contraction and extension of cardiomyocytes lead to the deformation cycles of the elastic butterfly wing matrices, which are associated with synchronous visually observable color change due to the photonic bandgap designed on the wings microstructure.

\section{Artificial hydrogel}

Compared to naturally derived bioactive hydrogels, artificial hydrogels have a better batch-to-batch property consistency and relatively low costs. However, they inherently lack cell attachment properties and thus are either modified with bioactive motifs or used as bioinert support. Examples of artificial hydrogels include poly(vinylidene fluoride) (PVDF), poly (3,4-ethylene dioxythiophene) (PEG), poly (3,4-ethylene dioxythiophene) (PEDOT), etc. Lahann et al. [159] designed a microcylinder and selectively coated one of its sides with bioactive FN for neonatal rat cardiomyocyte attachment, and the other side with bioinert PEG to avoid cell adherence (shown in Fig. 7a). The cardiomyocytes thus heterogeneously grow on one side of the cylinder and show a significant bending effect along the microcolumn. The contraction of the cardiomyocytes produces a force of $191 \mu \mathrm{N}$, which cannot be achieved by conventional actuators at the same scale ( $20 \mu \mathrm{m}$ in diameter and $78.5 \mu \mathrm{m}$ in length). Kim et al. [92] cultured C2C12 skeletal muscle cells on the surface of PEDOT functionalized by multiwalled carbon nanotubes (MWCNT) (shown in Fig. 7b) and successfully differentiated the skeletal muscle cells into muscle tubules after 7 days of culture. Due to the induction of carbon nanotubes, skeletal muscle tissue grows directionally in the direction parallel to the carbon nanotubes. Through applying a periodic voltage to the ribbon driver, the worm-like robot $(60 \mathrm{~mm}$ long and $10 \mathrm{~mm}$ wide) can contract and relax rhythmically. Moreover, its maximum contraction length can be adjusted between 0.2 and $0.7 \mathrm{~mm}$ by setting the period of the applied voltage. In the same year, Wang et al. [160] proposed a piezoelectric nano bio-generator made of cardiomyocytes embedded in fibrinogen modified polyvinylidene fluoride (PVDF-FN) hydrogels to actuate nanofibers (shown in Fig. 7c). Under the condition of $1.1 \mathrm{~Hz}$ spontaneous beating, the average voltage generated is $200 \mathrm{mV}$ and the current is $45 \mathrm{nA}$. Their model lays the foundation for bioenergy conversion and selfpropelled robot design and has the potential for application in biomechanical energy collection and the motion monitoring of humans.

\section{Tissue-harvested biomaterials}

The most biologically relevant materials for biobots are tissue-harvested biomaterials (such as decellularized extracellular matrix or similar commercial products), as they greatly resemble the composition of living tissues. Despite their high cost and low availability, many studies have attempted to use these highly active materials for biobot fabrication. Webster et al. [170] inoculated primary cardiomyocytes isolated from chicken embryos into a scaffold composed of electrochemically compacted and aligned collagen (ELAC), as shown in Fig. 7d. The micropatterned matrix promotes cell adhesion and induces cell arrangement. Under the action of electrical stimulation, the maximum speed of cardiomyocytes driven H-type stent reaches $34 \mu \mathrm{m} / \mathrm{min}$. Similarly, Bashir et al. [56] cultured muscle tissue by mold casting Matrigel, thrombin, and fibrinogen composite materials embedded with skeletal muscle cells. Therein, a platform was developed that links the computational modeling of the developed biobots with empirical verification. This platform not only tackles the thickness burden caused by limited nutrient diffusion-resulting in the expansion of thickness to $1.3 \mathrm{~cm}$ - but also guides the optimization of the force output of the autonomous hybrid skeletal muscle biobots (shown in Fig. 7e) from $200 \mu \mathrm{N}$ to $1.2 \mathrm{mN}$. Through this platform, the design can be virtually predicted and validated, which improves the forward engineering efficiency of such biological hybrid systems. Based on previous studies, Gillette et al. [58] cultured myoblasts in Matrigel and fibrinogen to form muscle tissue. The formed tissue was cocultured with a complete segment of the lumbar spinal cord of rats, forming a spinal robot (shown in Fig. 7f). The study demonstrated the engineering design of the first fully functional $3 \mathrm{D}$ neuromuscular junction that can not only respond to glutamate signals but also undergo nerve stimulation that leads to muscle contraction.

In summary, the selection or combination of substrate materials is dependent on the purpose of the designed biobot. The substrate materials and their macro- and microgeometric design can jointly affect the driving force and power density of biobots, and the combination of multiple materials 


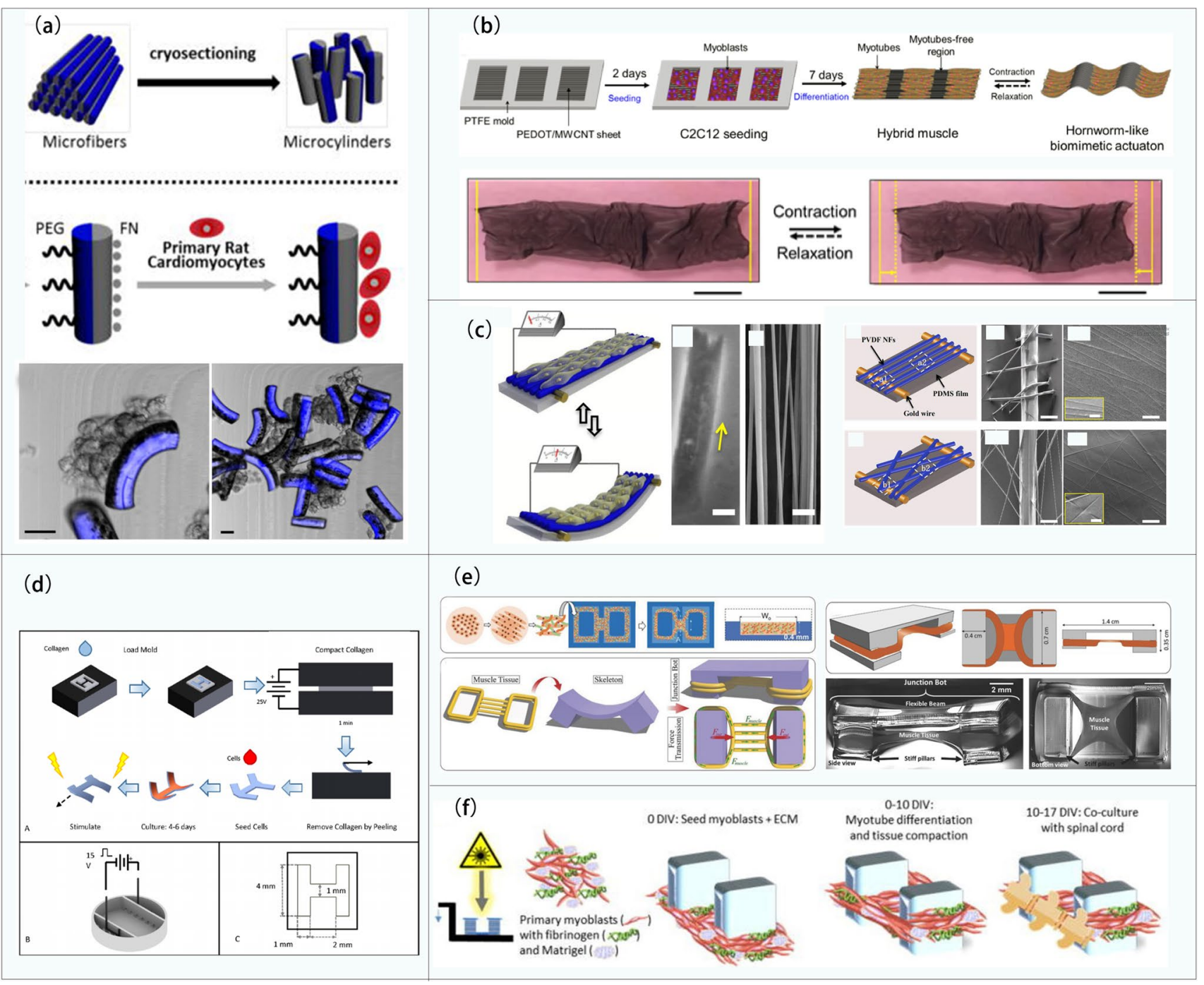

Fig. 7 Examples of biobots based on artificial hydrogel and decellularized extracellular matrix. a Microcylinders contracted by cardiomyocytes seeded on the non-PEGylated side of the microstructures (reproduced with permission Ref. [159]); b PEDOT/MWCNT sheet cultured with skeletal muscle cells and subjected to crawlingbased locomotion (reproduced with permission Ref. [92]); c a biogenerator driven by cardiomyocytes attached to PVDF-FN hydrogel (reproduced with permission Ref. [160]); d a miniature device in

to form composite multifunctional materials may be the new trend for future biobots.

\section{Structure and methods of control of biohybrid robots}

As a result of the rapid developments of biomaterials, biohybrid robots are increasingly showing incomparable advantages over rigid robots and even soft robots in terms which cardiomyocytes are inoculated into a scaffold made of ELAC (reproduced with permission Ref. [170]); e skeletal muscle cells are implanted into a mold of Matrigel, thrombin and fibrinogen to form muscle tissue (reproduced with permission Ref. [56]); f muscle formed by a tissue culture of myoblasts and Matrigel-fibrinogen was cocultured with a complete segment of rat lumbar spinal cord to form a biological robot (reproduced with permission Ref. [58])

of miniatured size and energy efficiency. To better simulate the motion of organisms in nature, synthetic materials are usually designed to harness desirable viscoelastic properties and fabricated into specific shapes, which determine biohybrid robot structures. In the robotics field, one of the indices to evaluate the complexity of a robot is via the number of independent movements it can achieve (also known as degree of freedom). Each of these independent movements can be controlled by numerous methods, such as physical or chemical stimulation. The next section aims 
to describe the latest progress regarding the degree of freedom and control methods of biobots.

\section{Degree of freedom (DOF) of biohybrid robots}

The number of independent movements a mechanism is capable of constitutes the degree of freedom of that mechanism. It is to be noted that an independent movement can be as simple as bending or twisting, but also as complex as the sinusoidal movement of a flexible fin. The key to judge the degree of freedom is to evaluate how many actuating sources can be individually controlled. Indeed, many real creatures can have over hundreds of DOFs, but the number of those in the emerging field of biohybrid robots is rather limited. The next section overviews three categories of biobots in this regard: those with single-, double-, and multi-DOF.

\section{Single-DOF}

Due to the infancy state of biobots, most of them developed to date feature a single DOF. For example, micropumps driven by cardiomyocytes $[100,161]$, biobots made from
California sea hare I 2 muscles [174], and robots driven by a single $E$. coli [175] are all single-DOF structures. Dokmeci et al. [164] creatively designed a biological driver with a four-layer structure through a bottom-up approach, which is composed of PEG hydrogel, carbon nanotube array, CNTGelMA, and myocardial tissue. As the muscle formed by the driver structure is integrated, it can achieve spontaneous contraction and act as a single driver. Alternatively, the biological driver can be controlled by external electric fields of an integrated conductive carbon nanotube microelectrode array. Using a similar approach, Khademhosseini et al. [165] used a multilayer skeleton as the structure of a fish-like robot. Cardiomyocytes were added to a skeleton composed of PEG, Au microelectrodes, and CNT-GelMA hydrogel (shown in Fig. 8a). The muscles differentiated from cardiomyocytes could provide self-excited motion in the identical direction, driving the skeleton as a whole to make a stroke-like movement.

In addition to those driven by cardiomyocytes, singleDOF biobots driven by $\mathrm{C} 2 \mathrm{C} 12$ skeletal muscle, DV tissue, and microorganisms, have also been constructed. Saif et al. [17] cultured C2C12 skeletal muscle cells on a PDMS mold

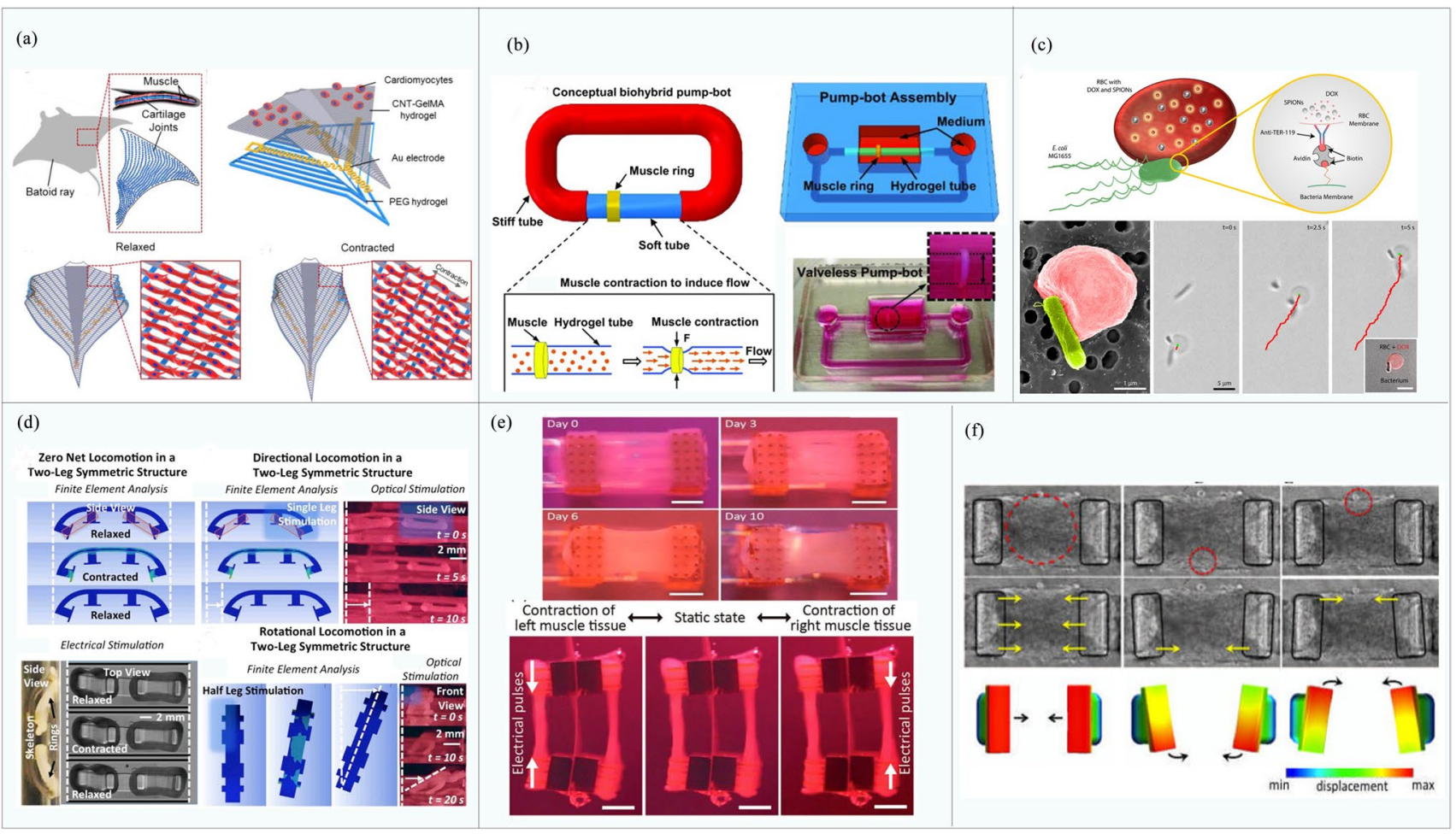

Fig. 8 Examples of biobots based on structure. a Single-DOF bionic fish with a four-layer structure (reproduced with permission Ref. [165]); b a biological device with single-DOF flow formed by the eccentric placement of the muscle ring and the connection between the hose and the rigid tube (reproduced with permission Ref. [17]); c single-DOF microbial robot driven by a single Escherichia coli (reproduced with permission Ref. [173]); $\mathbf{d}$ a quadruped beam robot that can be controlled separately by a single muscle ring and a half muscle ring (reproduced with permission Ref. [45]); e a biological device driven bidirectionally by a pair of antagonistic skeletal muscle tissue components (reproduced with permission Ref. [147]); f structure of a multi-DOF biped beam robot that can realize several degrees of freedom motion under light stimulation (reproduced with permission Ref. [169]) 
to form a muscle ring, which was placed on a hydrogel tube to form a pump-robot, as shown in Fig. 8b. In this design, under electrical stimulation, the muscle ring contracts as a whole. The one-way net flow of the pump can be achieved through the eccentric placement of the muscle ring and the connection between a hose and a rigid pipe. An autonomous swimming robot designed by Morishima et al. [62] is driven by an overall autonomous pulse organized by a DV tissue. Sitti et al. [173] first developed the red blood cell (RBC) microswimmer, which is a red blood cell driven by a single E. coli, as shown in Fig. 8c. Although there is only one driving source, it achieves multiple functions, for example, large deformation in a channel and retention after squeezing through, as well as magnetic maneuverability, etc.

\section{Double-DOF}

The research on double degrees of freedom is mainly found on muscular drives in the existing literature. As mentioned in the previous example, the quadruped robot developed by Bahir's team [45] is shown in Fig. 8d. By stimulating a single and half muscle ring separately under the condition of $460 \mathrm{~nm}$ light, bidirectional and steering movements can be realized. Takeuchi et al. [147] have developed a pair of antagonistic skeletal muscle tissue-driven double-DOF biological grasp handles, as shown in Fig. 8e. Skeletal muscle tissues are cultured on both sides of a flexible substrate, and different movements can be achieved by electrically stimulating the corresponding side of the antagonistically aligned muscle tissues. When both skeletal muscle tissues have the same size, the handle can symmetrically bend to either side. If they are of different sizes, large-angle bending in one direction can be achieved.

\section{Multi-DOF}

Real creatures in nature have multiple degrees of freedom; the developmental trend of biobots is to achieve the multiDOF movements of real organisms. However, challenges are significant and there are merely a few published works to date on multi-DOF biobots. Asada et al. [169] developed a multi-DOF biped robot driven by muscles formed by $\mathrm{C} 2 \mathrm{C} 12$ cells that had been genetically modified to manifest photosensitivity, as shown in Fig. 8f. Using light stimulation, local stimulation of a certain part of the biobot can be carried out, thus achieving multiple degrees of freedom, such as translational and torsional motion. Light stimulation has accurate space-time control, which can be used as a reference for the follow-up research of complex mobile robots. Since then, a batfish robot [81], as mentioned earlier, has been designed as a multi-DOF robot (Fig. 2c). The muscle tissue of this robot can be separately controlled, and it can swim like a real fish by locally stimulating and moving the light spot position.

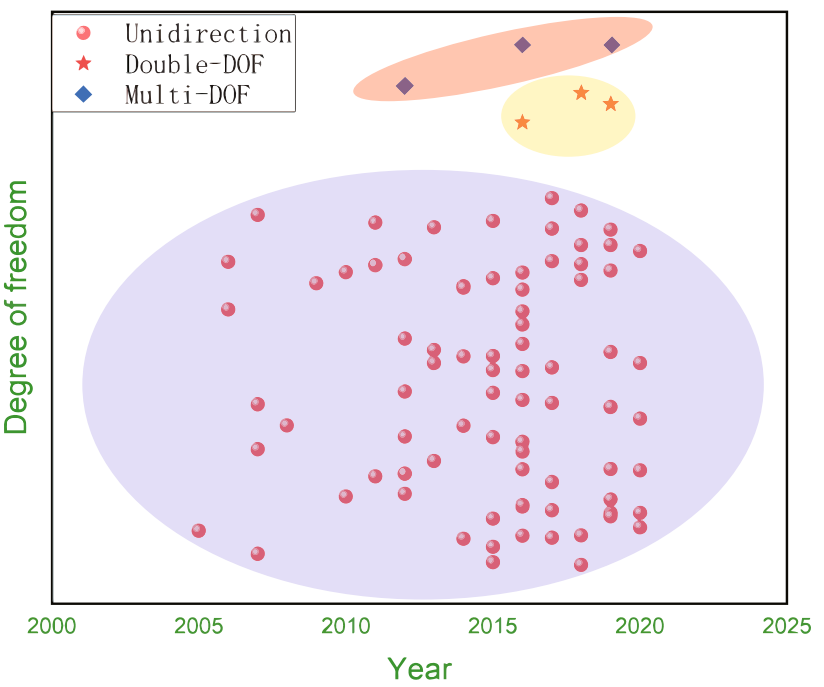

Fig. 9 The amount of recent literature on biological robots with different degrees of freedom, including single-, double-, and multi-DOF biobots

At present, single-DOF biobots still account for the majority of biological robots in relevant research, as shown in Fig. 9. Meanwhile, novel multi-DOF biobots are attracting growing interest, with a number of driving/control mechanisms already proven as versatile.

\section{Stimulation of biobots}

The controllability of biobots is important for their ability to perform desirable tasks. Most biological cells/organisms can respond to chemical, electrical, and other stimuli, which can be used to actuate the biobots to achieve different forms of movements, such as swimming [95, 123, 124], walking [51, 53, 171], and grasping [85, 86, 105]. Furthermore, the electrical stimulation and mechanical stretching of muscle tissue in the process of culturing can train muscles, promote the arrangement and differentiation of muscle tissue, and subsequently increase the driving force [176-181]. Existing control methods can be generally classified into physical and chemical stimulation.

\section{Physical stimulation}

The main control method of biobots is physical stimulation, including electrical, optical, temperature, magnetic stimulation, etc., with electrical stimulation being the most commonly used one. It is well-known that the contraction and relaxation of muscles in vivo, especially of skeletal muscles, are triggered by the transmission of bioelectrical signals. In a similar fashion, external electrical stimulation can effectively control biobots. Liu et al. [171] proposed a circular distributed multielectrodes (CEs) method, based on which 


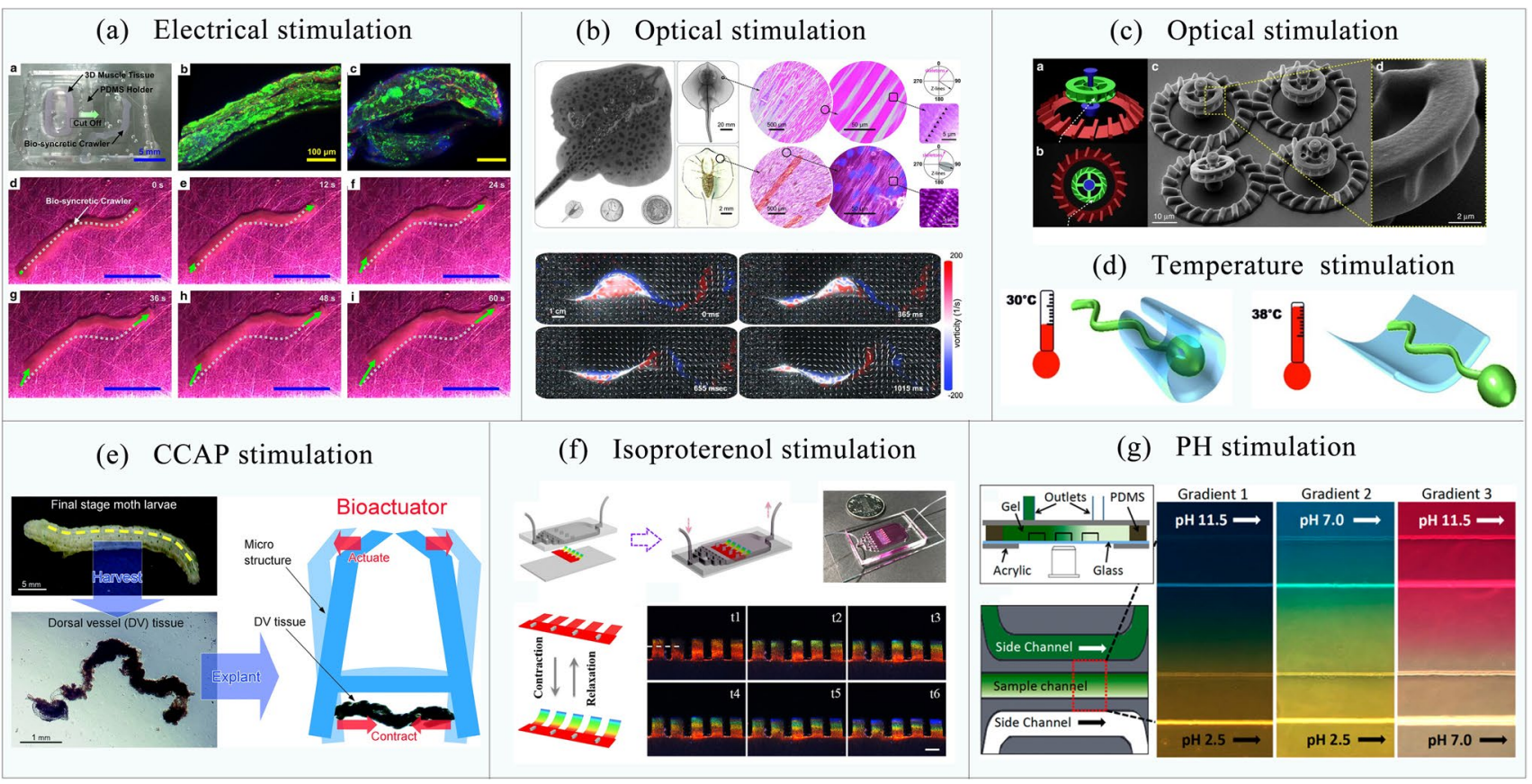

Fig. 10 Examples of biobots based on various types of stimulation. a Electrical stimulation of crawling robot by the CEs method (reproduced with permission Ref. [171]); b a bionic fish that can swim forward depending on the undulation of its fins under optical guidance (reproduced with permission Ref. [81]); c optically guided threedimensional device incorporating microorganisms (reproduced with permission Ref. [182]); d the contraction and extension of microtubules are realized through a sperm robot controlled by temperature (reproduced with permission Ref. [183]); e crustacean cardioactive peptide (CCAP) guided DV tissue contraction to realize the control of micro-tweezers (reproduced with permission Ref. [184]); $\mathbf{f}$ the biological hybrid hydrogel integrated into the microfluidic chip bends through chemical inducers and leads to color change (reproduced with permission Ref. [167]); g three different $\mathrm{pH}$ solubility channels were used to test the $\mathrm{pH}$ induction characteristics of the micro-robot (reproduced with permission Ref. [185])

example, Park et al. [81] developed a stingray-like biobot with cellular engineered cardiomyocytes to achieve optical controllability. Through selectively arranging the cardiomyocytes on the flexible fin of the stingray, it is possible to optically guide a designated part of the fin to perform timed and patterned flapping, resulting in the forward swimming of the biobot, as shown in Fig. 10b. In addition to muscle drives, microbes can also be optically guided. Di Leonardo et al. [182] developed a fast, silent micromotor self-assembled by E. coli expressing proteorhodopsin and a 3D micro-scaffold, as shown in Fig. 10c. This structure can capture the bacteria in the microcavity array and maximize the torque generated by their motion. Under the action of optical stimulation and feedback loop, the speed of the micromotor can be dynamically controlled and the synchronization of multiple micromotors can also be realized.

Electrical stimulation and optical guidance are the generally used control methods for muscle tissue-driven biobots. However, microorganisms, sperm, and other biobots are more responsive to magnetic, temperature, and other stimuli. Sanchez et al. [175] attached $E$. coli to $2 \mu \mathrm{m}$ large Janus particles (Pt/PS) to form a simple biological microswimmer that achieves directional movements under the guidance of the 
magnetic field. Using temperature response, Schmidt et al. [183] controlled a sperm robot captured by a microtubule. When the temperature drops below $30^{\circ} \mathrm{C}$, the microtubule contracts and captures a sperm to form a sperm aggregation robot that can swim directionally. Upon the rise of temperature to above $38^{\circ} \mathrm{C}$, the microtubule unfolds and releases the sperm, as shown in Fig. 10d.

\section{Chemical stimulation}

Chemical stimulation has advantages over physical stimulation due to the smaller electrical damage or biological modification. Although its time resolution is relatively low, it may be the preferred choice when precise control is not required. Based on their previous research, Morishima et al. [184] designed a biobot driven by DV tissue using chemical stimulation (shown in Fig. 10e). When the crustacean cardioactive peptide (CCAP) is stimulated, the contractile frequency immediately increases to the maximum. Besides, all tested concentrations of CCAP produce the maximum contractile frequency response in $1 \mathrm{~min}$ regardless of a significant change of contractile force. Zhao et al. [167] presented an integrated microfluidic platform driven by cardiomyocytes, as shown in Fig. 10f. When different concentrations of isoproterenol are injected into the microfluidic platform, the structure made of color switchable hydrogels changes accordingly. Tuning the concentration of isoproterenol affects the decolorization of the platform, coupled with a regulation of the beating frequency of the cardiomyocytes. In addition to using chemical attractants, $\mathrm{pH}$ regulation can also be availed. Sitti et al. [185] attached multiple S. marcescens cells to a polystyrene ball with a diameter of $3 \mu \mathrm{m}$ to make a miniature swimming robot and achieved $\mathrm{pH}$ gradient dependent movements of the robot (as shown in Fig. 10g). This study suggests a possible way to control biobots by $\mathrm{pH}$ and chemotaxis and provides new approaches for follow-up research.

\section{Potential applications and challenges of biohybrid robots}

Living material-based biohybrid robots appear highly promising as possible solutions to overcome the drawbacks of currently available artificial actuation technologies. Future biohybrid robots may integrate a variety of cell and tissue types, including neural networks for sensing and processing information, as well as vascular networks for transporting nutrients, oxygen, and other biochemical factors [91]. These types of biohybrid robots encapsulate sensors, drivers, actuators, and control systems in a single unit, and feature not only advantageous controllability and output force than conventional rigid bots, but also intriguing capabilities such as self-assembly, self-repair, multi-degree of freedom, intelligent sensing, and efficient energy conversion. These bots can act highly similarly to real creatures in nature, leading to numerous potential applications in the fields of mechanics, computation, biomedical engineering, and many other areas.

\section{Potential applications in the field of biomedicine}

First, due to their miniaturization, high biocompatibility, and biodegradability, biobots are highly suitable for entering the circulation system for disease monitoring and diagnostics. After the completion of tasks, biobots can safely self-dissolve or self-degrade. Second, the controllability of biohybrid robots makes them an ideal choice for directional drug delivery, which is specifically useful for tumor treatment. Most current chemotherapeutic treatments can harm normal cells while destroying tumors, causing considerable side effects to patients. Meanwhile, drug delivery in targeted therapy can be achieved through biohybrid robots driven by microorganisms [122, 125, 173], which can be efficiently loaded with drugs and powered by the surrounding biological fluids. Moreover, an integrated microchip system (or known as "lab on a chip") may be used as a platform for drug development and toxicity testing. In recent years, attempts have been made to introduce muscle-driven bio-integrated devices into microfluidic chips, such as the microfluidic chips designed by Zhao et al. in 2018 and 2020 $[53,75]$. The device revealed that the beating frequency of cardiomyocytes is positively correlated with the addition of isoproterenol. As a result, the effect of isoproterenol on a human heart was also established. At the same time, the platform is suitable for testing other drugs, and may even replace animal trials in the future.

\section{Potential applications in the field of machinery}

Nowadays, many robots are still driven by traditional drives. Biohybrid-driven robots, however, can generate the same driving force while achieving lower mass and higher efficiency. Muscle cells are readily available, inexpensive, and self-proliferative, such that the cost of mechanical products can be greatly reduced. Besides, the energy source of biohybrid robots comes from green energy sources such as glucose and adenosine triphosphate (ATP), which may greatly contribute to pollution reduction. Finally, future mechanical products driven by muscles may feature self-repair capability the same way as their source organisms, leading to significantly increased damage resistance and enhanced lifespan.

In addition to the abovementioned fields, the future uses of muscular driven biobots may include earthquake rescue 
exploration, battlefield reconnaissance, and even application in daily routine vehicles.

Nonetheless, current biological drivers still encounter many challenges:

1. Related ethical problems persist, such as the extraction of primary cells from mammals or muscle tissues directly extracted from living larvae and other animals. One possible approach to circumvent this problem is to induce the differentiation of multifunctional stem cells [59]. However, this method has shortcomings, such as limited force versus their natural counterparts, as well as costly and tedious procedures to obtain substantial quantities of such cells. These drawbacks may be successfully addressed by further research in tissue engineering.

2. Lack of intelligent perception of the external environment for adaptive control. At present, research on biobots mainly focuses on their drivers, while the functions of intelligent perception and intelligent control are lacking. Future biobots may therefore integrate intelligent sensing functions, where the robot drives the actuator and realizes the corresponding motion by perceiving external sensor signals and transferring them to the control system to form a closed-loop feedback. Attention may also be paid to using tools such as genetic engineering or biological integration to explore new functions of biomaterials.

3. Nutrient transport and environmental regulation of biomaterials. Mammalian cells, the most commonly used cell types for biobots, need specific culture conditions (e.g., medium components, temperature, $\mathrm{pH}$ ) to survive, and the nutrients/wastes and $\mathrm{O}_{2} / \mathrm{CO}_{2}$ must be regularly exchanged. In vitro muscle tissues are supported by vasculature, which is the ideal means for nutrient and gas exchange. Regardless, some pioneering works have managed to achieve ambient air-compatible biobot movements, but research on the structure, lifespan, and motion patterns of these biobots is still in its infancy. Biobots suitable for various environmental conditions could be developed in the future with a combination of emerging mechanical, chemical or material alternatives, and tissue engineering technology.

4. The limited lifespan of biobots. Existing mammal-driven biological robots have a short lifespan, which is usually under a few days to two weeks. There are many reasons for this limitation, such as the spontaneous contraction of skeletal muscle tissue during culture leading to a deterioration of robot performance, a fixed structure that limits the self-repair of muscle injury, and the environment dissimilar to in vivo conditions. An extended lifespan could manifest in the lower production cost of biobots, thus making them economically more competitive than conventional bots. Looking ahead, more studies may be focused on extending the lifespan of multicellular biobots and understanding the corresponding underlying mechanisms.

5. At present, most biobots have simple functions and limited degrees of freedom and are monofunctional, such as swimming, grasping, or contracting/stretching bio-robots, which can be only controlled as a whole. Research can be implemented to develop biobots that can integrate multiple functions and achieve multi-DOF movements in changing environments. This challenge may be overcome by the coculturing of cells or by the independent control of specific parts of the biobot muscle tissue.

\section{Summary and perspectives}

The rapid developments of biobots has opened up new possibilities full of excitement and challenges. Compared to conventional rigid drives and soft material drives, biodrives have the advantages of energy efficiency, reliability, and power density at miniature scales. This paper summarized the power sources, supporting biomaterials and structures of biobots with the associated control methods and the demonstration of the latest developments in the field of bio-robotics. It is considered that biobots have huge potential value and many future applications. Nevertheless, challenges exist in terms of ethics, intelligence, nutrient transport, lifespan, and the complexity level of biobots.

Biological robots involve the interdisciplinary integration of machinery, material science, chemistry, physics, biology, control science, and so on. The advances of each of these fields can also positively support the developmental progress of biobots. Nowadays, bio-robots are still far from their envisaged purposes, and some major challenges cannot be solved by the solutions provided by biotechnology or manufacturing technology alone, but rather by the joint efforts of all of the involved research fields. Despite that many challenges need to be overcome, current biobots have also made exciting progress and laid the foundations of further research and applications.

At present, research on biobots is mainly conducted in the field of biomedicine, though the intriguing driving performance of biological drivers would prove widely popular in various other fields. The authors hope that this review can provide some inspiration to researchers and actively expand the scope of practical applications of biobots in many potentially relevant fields.

Acknowledgements This work was supported by the Research Project Funding of National University of Defense Technology of China (No. ZK19-33) and the National Postdoctoral International Exchange 
Program Funding for Incoming Postdoctoral Students (postdoctoral No. 48127).

Author contributions $\mathrm{ZNL}$ investigated and summarized the literature and wrote the original draft. JZS and TJ helped revise the paper and gave some advice. JZS and TJ supervised and applied for funds. All authors have read and approved this manuscript for publication.

\section{Declarations}

Conflict of interest The authors declare that there is no conflict of interest.

Ethical approval This study does not contain any studies with human or animal subjects performed by any of the authors.

Open Access This article is licensed under a Creative Commons Attribution 4.0 International License, which permits use, sharing, adaptation, distribution and reproduction in any medium or format, as long as you give appropriate credit to the original author(s) and the source, provide a link to the Creative Commons licence, and indicate if changes were made. The images or other third party material in this article are included in the article's Creative Commons licence, unless indicated otherwise in a credit line to the material. If material is not included in the article's Creative Commons licence and your intended use is not permitted by statutory regulation or exceeds the permitted use, you will need to obtain permission directly from the copyright holder. To view a copy of this licence, visit http://creativecommons.org/licenses/by/4.0/.

\section{References}

1. Appiah C, Arndt C, Siemsen K et al (2019) Living materials herald a new era in soft robotics. Adv Mater 31(36):e1807747. https://doi.org/10.1002/adma.201807747

2. Webster-Wood VA, Akkus O, Gurkan UA et al (2017) Organismal engineering: toward a robotic taxonomic key for devices using organic materials. Sci Robot 2(12):18. https://doi.org/10. 1126/scirobotics.aap9281

3. Peter AK, Bjerke MA, Leinwand LA (2016) Biology of the cardiac myocyte in heart disease. Mol Biol Cell 27(14):2149-2160. https://doi.org/10.1091/mbc.E16-01-0038

4. Go G, Jeong SG, Yoo A et al (2020) Human adipose-derived mesenchymal stem cell-based medical microrobot system for knee cartilage regeneration in vivo. Sci Robot 5(38):15. https:// doi.org/10.1126/scirobotics.aay6626

5. Jeong J, Jang D, Kim D et al (2020) Acoustic bubble-based drug manipulation: carrying, releasing and penetrating for targeted drug delivery using an electromagnetically actuated microrobot. Sens Actuator A Phys 306:9. https://doi.org/10.1016/j.sna.2020. 111973

6. Bhushan P, Tomlin C (2020) Design of an electromagnetic actuator for an insect-scale spinning-wing robot. IEEE Robot Autom Lett 5(3):4188-4193. https://doi.org/10.1109//ra.2020.2990886

7. Jafferis NT, Helbling EF, Karpelson M et al (2019) Untethered flight of an insect-sized flapping-wing microscale aerial vehicle. Nature 570(7762):491-495. https://doi.org/10.1038/ s41586-019-1322-0

8. Phan HV, Kang T, Park HC (2017) Design and stable flight of a $21 \mathrm{~g}$ insect-like tailless flapping wing micro air vehicle with angular rates feedback control. Bioinspir Biomim 12(3):1-17. https://doi.org/10.1088/1748-3190/aa65db
9. Helps T, Taghavi M, Wang SH et al (2020) Twisted rubber variable-stiffness artificial muscles. Soft Robot 7(3):386-395. https:// doi.org/10.1089/soro.2018.0129

10. Mishra AK, Wallin TJ, Pan WY et al (2020) Autonomic perspiration in 3D-printed hydrogel actuators. Sci Robot 5(38):9. https:// doi.org/10.1126/scirobotics.aaz3918

11. Shahsavan H, Aghakhani A, Zeng H et al (2020) Bioinspired underwater locomotion of light-driven liquid crystal gels. PNAS 117(10):5125-5133. https://doi.org/10.1073/pnas.1917952117

12. Ge FJ, Zhao Y (2020) Microstructured actuation of liquid crystal polymer networks. Adv Funct Mater 30(2):19. https://doi.org/10. 1002/adfm.201901890

13. Li P, Wang Y, Gupta U et al (2019) Transparent soft robots for effective camouflage. Adv Funct Mater 29(37):1902098. https:// doi.org/10.1002/adfm.201901908

14. Kriegman S, Blackiston D, Levin M et al (2020) A scalable pipeline for designing reconfigurable organisms. PNAS 117(4):18531859. https://doi.org/10.1073/pnas.1910837117

15. Singh AV, Ansari MHD, Mahajan M et al (2020) Sperm cell driven microrobots-emerging opportunities and challenges for biologically inspired robotic design. Micromachines 11(4):1-17. https://doi.org/10.3390/mi11040448

16. Xu HF, Medina-Sanchez M, Magdanz V et al (2018) Spermhybrid micromotor for targeted drug delivery. ACS Nano 12(1):327-337. https://doi.org/10.1021/acsnano.7b06398

17. Li ZW, Seo Y, Aydin O et al (2019) Biohybrid valveless pumpbot powered by engineered skeletal muscle. PNAS 116(5):15431548. https://doi.org/10.1073/pnas.1817682116

18. de Avila BEF, Gao WW, Karshalev E et al (2018) Cell-like micromotors. Accounts Chem Res 51(9):1901-1910. https:// doi.org/10.1021/acs.accounts.8b00202

19. Amirhosseini H, Najafi F (2020) Design, prototyping and performance evaluation of a bio-inspired walking microrobot. Iran J Sci Technol Trans Mech Eng 44(3):799-811. https://doi.org/ 10.1007/s40997-019-00281-4

20. Karasek M, Muijres FT, De Wagter C et al (2018) A tailless aerial robotic flapper reveals that flies use torque coupling in rapid banked turns. Science 361(6407):1089-1094. https://doi. org/10.1126/science.aat0350

21. Rus D, Tolley MT (2015) Design, fabrication and control of soft robots. Nature 521(7553):467-475. https://doi.org/10.1038/natur e14543

22. Roche ET, Wohlfarth R, Overvelde JT et al (2014) A bioinspired soft actuated material. Adv Mater 26(8):1200-1206. https://doi. org/10.1002/adma.201304018

23. Tu Z, Fei F, Deng XY (2020) Untethered flight of an at-scale dual-motor hummingbird robot with bio-inspired decoupled wings. IEEE Robot Autom Lett 5(3):4194-4201. https://doi.org/ 10.1109/lra.2020.2974717

24. Vo VTK, Ang MHA, Koh SJA (2020) Maximal performance of an antagonistically coupled dielectric elastomer actuator system. Soft Robot. https://doi.org/10.1089/soro.2019.0176

25. Ji XB, Liu XC, Cacucciolo V et al (2019) An autonomous untethered fast soft robotic insect driven by low-voltage dielectric elastomer actuators. Sci Robot 4(37):11. https://doi.org/10.1126/ scirobotics.aaz6451

26. Li TF, Zou ZA, Mao GY et al (2019) Agile and resilient insectscale robot. Soft Robot 6(1):133-141. https://doi.org/10.1089/ soro.2018.0053

27. Yang X, Chang L, Pérez-Arancibia NO (2020) An 88-milligram insect-scale autonomous crawling robot driven by a catalytic artificial muscle. Sci Robot 5(45):eaba0015. https://doi.org/10.1126/ scirobotics.aba0015

28. Coyle S, Majidi C, LeDuc P et al (2018) Bio-inspired soft robotics: material selection, actuation, and design. Extreme Mech Lett 22:51-59. https://doi.org/10.1016/j.eml.2018.05.003 
29. Kim S, Laschi C, Trimmer B (2013) Soft robotics: a bioinspired evolution in robotics. Trends Biotechnol 31(5):23-30. https://doi. org/10.1016/j.tibtech.2013.03.002

30. Guo YB, Shahsavan H, Sitti M (2020) Microscale polarization color pixels from liquid crystal elastomers. Adv Opt Mater 8(17):1902098. https://doi.org/10.1002/adom.201902098

31. Zmyslony M, Dradrach K, Haberko J et al (2020) Optical pliers: micrometer-scale, light-driven tools grown on optical fibers. Adv Mater 32(33):2002779. https://doi.org/10.1002/adma.202002779

32. Ahn CY, Liang XD, Cai SQ (2019) Bioinspired design of lightpowered crawling, squeezing, and jumping untethered soft robot. Adv Mater Technol 4(7):9. https://doi.org/10.1002/admt.20190 0185

33. Wang CJ, Sim K, Chen J et al (2018) Soft ultrathin electronics innervated adaptive fully soft robots. Adv Mater 30(13):9. https://doi.org/10.1002/adma.201706695

34. Chen Y, Zhao H, Mao J et al (2019) Controlled flight of a microrobot powered by soft artificial muscles. Nature 575(7782):324329. https://doi.org/10.1038/s41586-019-1737-7

35. Kim SH, Kim DY, Lim TH et al (2020) Silk fibroin bioinks for digital light processing (DLP) 3D bioprinting. Adv Exp Med Biol 1249:53-66. https://doi.org/10.1007/978-981-15-3258-0_4

36. Jeon O, Bin Lee Y, Hinton TJ et al (2019) Cryopreserved cellladen alginate microgel bioink for 3D bioprinting of living tissues. Mater Today Chem 12:61-70. https://doi.org/10.1016/j. mtchem.2018.11.009

37. Jiang T, Munguia-Lopez JG, Flores-Torres S et al (2019) Extrusion bioprinting of soft materials: an emerging technique for biological model fabrication. Appl Phys Rev 6(1):011310. https:// doi.org/10.1063/1.5059393

38. Duan CM, Ren HX, Gao S (2010) Insulin-like growth factors (IGFs), IGF receptors, and IGF-binding proteins: roles in skeletal muscle growth and differentiation. Gen Comp Endocrinol 167(3):344-351. https://doi.org/10.1016/j.ygcen.2010.04.009

39. Vunjak-Novakovic G, Tandon N, Godier A et al (2010) Challenges in cardiac tissue engineering. Tissue Eng Part B Rev 16(2):169-187. https://doi.org/10.1089/ten.teb.2009.0352

40. Yang GZ, Bellingham J, Dupont PE et al (2018) The grand challenges of science robotics. Sci Robot 3(14):eaar7650. https://doi. org/10.1126/scirobotics.aar7650

41. Ceylan H, Giltinan J, Kozielski K et al (2017) Mobile microrobots for bioengineering applications. Lab Chip 17(10):17051724. https://doi.org/10.1039/c7lc00064b

42. Feinberg AW (2015) Biological soft robotics. In: Yarmush ML (ed). Annu Rev Biomed Eng 17:243-265. https://doi.org/10. 1146/annurev-bioeng-071114-040632

43. Ricotti L, Fujie T (2017) Thin polymeric films for building biohybrid microrobots. Bioinspir Biomim 12(2):16. https://doi.org/ 10.1088/1748-3190/aa5e 5f

44. Shimizu M, Miyasaka K, Miyamoto K et al (2013) Muscle tissue actuator driven with light-gated ion channels channelrhodopsin. Proc CIRP. https://doi.org/10.1016/j.procir.2013.01.034

45. Raman R, Cvetkovic C, Uzel SG et al (2016) Optogenetic skeletal muscle-powered adaptive biological machines. PNAS 113(13):3497-3502. https://doi.org/10.1073/pnas.1516139113

46. Carlsen RW, Sitti M (2014) Bio-hybrid cell-based actuators for microsystems. Small 10(19):3831-3851. https://doi.org/10.1002/ smll.201400384

47. Sun LY, Yu YR, Chen ZY et al (2020) Biohybrid robotics with living cell actuation. Chem Soc Rev 49(12):4043-4069. https:// doi.org/10.1039/d0cs00120a

48. Chan V, Asada HH, Bashir R (2014) Utilization and control of bioactuators across multiple length scales. Lab Chip 14(4):653670. https://doi.org/10.1039/c31c50989c

49. Duffy RM, Feinberg AW (2014) Engineered skeletal muscle tissue for soft robotics: fabrication strategies, current applications, and future challenges. Wires Nanomed Nanobi 6(2):178-195. https://doi.org/10.1002/wnan.1254

50. Xi J, Schmidt JJ, Montemagno CD (2005) Self-assembled microdevices driven by muscle. Nat Mater 4(2):180-184. https://doi org/10.1038/nmat 1308

51. Morimoto Y, Onoe H, Takeuchi S (2020) Biohybrid robot with skeletal muscle tissue covered with a collagen structure for moving in air. APL Bioeng 4(2):026101. https://doi.org/10.1063/1. 5127204

52. Tanaka N, Yamashita T, Yalikun Y et al (2019) An ultra-small fluid oscillation unit for pumping driven by self-organized threedimensional bridging of pulsatile cardiomyocytes on elastic micropiers. Sens Actuators B Chem 293:256-264. https://doi. org/10.1016/j.snb.2019.04.087

53. Sun LY, Chen ZY, Bian FK et al (2020) Bioinspired soft robotic caterpillar with cardiomyocyte drivers. Adv Funct Mater 30(6):8. https://doi.org/10.1002/adfm.201907820

54. Xu BZ, Han XM, Hu YW et al (2019) A remotely controlled transformable soft robot based on engineered cardiac tissue construct. Small 15(18):10. https://doi.org/10.1002/smll.201900006

55. Yamatsuta E, Beh SP, Uesugi K et al (2019) A micro peristaltic pump using an optically controllable bioactuator. Engineering 5(3):580-585. https://doi.org/10.1016/j.eng.2018.11.033

56. Pagan-Diaz GJ, Zhang X, Grant L et al (2018) Simulation and fabrication of stronger, larger, and faster walking biohybrid machines. Adv Funct Mater 28(23):1801145. https://doi.org/10. 1002/adfm.201801145

57. Hasebe A, Suematsu Y, Takeoka S et al (2019) Biohybrid actuators based on skeletal muscle-powered microgrooved ultrathin films consisting of poly(styrene-block-butadiene-block-styrene). ACS Biomater Sci Eng 5(11):5734-5743. https://doi.org/10. 1021/acsbiomaterials. 8 b01550

58. Kaufman CD, Liu SC, Cvetkovic C et al (2020) Emergence of functional neuromuscular junctions in an engineered, multicellular spinal cord-muscle bioactuator. APL Bioeng 4(2):026104 https://doi.org/10.1063/1.5121440

59. Tanaka Y, Yanagisawa Y, Kitamori T (2011) Fluid actuation for a bio-micropump powered by previously frozen cardiomyocytes directly seeded on a diagonally stretched thin membrane. Sens Actuators B Chem 156(1):494-498. https://doi.org/10.1016/j. snb.2011.04.055

60. Uesugi K, Sakuma Y, Akiyama Y et al (2019) Temperatureresponsive culture surfaces for insect cell sheets to fabricate a bioactuator. Adv Robot 33(5):219-231. https://doi.org/10.1080/ 01691864.2019.1568908

61. Touyama Y, Hoshino T, Iwabuchi K et al (2009) Micro-encapsulation of bio-actuator using insect dorsal vessel. In: Ann MHS micro-nano global COE, international symposium on micronanomechatronics and human science, pp 644-649. https://doi. org/10.1109/MHS.2009.5351970

62. Yalikun Y, Uesugi K, Hiroki M et al (2019) Insect muscular tissue-powered swimming robot. Actuators 8(2):15. https://doi. org/10.3390/act8020030

63. Akiyama Y, Iwabuchi K, Furukawa Y et al (2010) Electrical stimulation of cultured lepidopteran dorsal vessel tissue: an experiment for development of bioactuators. Vitro Cell Dev Biol Anim 46(5):411-415. https://doi.org/10.1007/s11626-009-9268-4

64. Hosseinidoust Z, Mostaghaci B, Yasa O et al (2016) Bioengineered and biohybrid bacteria-based systems for drug delivery. Adv Drug Deliv Rev 106:27-44. https://doi.org/10.1016/j.addr. 2016.09.007

65. Li D, Choi H, Cho S et al (2015) A hybrid actuated microrobot using an electromagnetic field and flagellated bacteria for tumortargeting therapy. Biotechnol Bioeng 112(8):1623-1631. https:// doi.org/10.1002/bit.25555 
66. Felfoul O, Mohammadi M, Taherkhani S et al (2016) Magnetoaerotactic bacteria deliver drug-containing nanoliposomes to tumour hypoxic regions. Nat Nanotechnol 11(11):941-947. https://doi.org/10.1038/nnano.2016.137

67. Uthaman S, Zheng S, Han J et al (2016) Preparation of engineered salmonella typhimurium-driven hyaluronic-acid-based microbeads with both chemotactic and biological targeting towards breast cancer cells for enhanced anticancer therapy. Adv Healthc Mater 5(2):288-295. https://doi.org/10.1002/adhm. 201500556

68. Di Leonardo R, Angelani L, Dell'Arciprete D et al (2010) Bacterial ratchet motors. PNAS 107(21):9541-9545. https://doi.org/ 10.1073/pnas.0910426107

69. Zhang C, Wang WX, Xi N et al (2018) Development and future challenges of bio-syncretic robots. Engineering 4(4):452-463. https://doi.org/10.1016/j.eng.2018.07.005

70. Magdanz V, Medina-Sanchez M, Schwarz L et al (2017) Spermatozoa as functional components of robotic microswimmers. Adv Mater 29(24):18. https://doi.org/10.1002/adma.201606301

71. Magdanz V, Sanchez S, Schmidt OG (2013) Development of a sperm-flagella driven micro-bio-robot. Adv Mater 25(45):6581-6588. https://doi.org/10.1002/adma.201302544

72. Kennedy LC, Bear AS, Young JK et al (2011) T cells enhance gold nanoparticle delivery to tumors in vivo. Nanoscale Res Lett 6:11. https://doi.org/10.1186/1556-276x-6-283

73. Song TJ, Liang HJ (2013) Capability of DNA-fueled molecular machine in tuning association rate of DNA-functionalized gold nanoparticles. Chin J Polym Sci 31(9):1183-1189. https://doi. org/10.1007/s10118-013-1319-3

74. Chen ZY, Fu FF, Yu YR et al (2019) Cardiomyocytes-actuated Morpho butterfly wings. Adv Mater 31(8):7. https://doi.org/10. 1002/adma.201805431

75. Shang YX, Chen ZY, Fu FF et al (2019) Cardiomyocyte-driven structural color actuation in anisotropic inverse opals. ACS Nano 13(1):796-802. https://doi.org/10.1021/acsnano.8b082 30

76. Holley MT, Nagarajan N, Danielson C et al (2016) Development and characterization of muscle-based actuators for selfstabilizing swimming biorobots. Lab Chip 16(18):3473-3484. https://doi.org/10.1039/c6lc00681g

77. Yin S, Zhang X, Zhan C et al (2005) Measuring single cardiac myocyte contractile force via moving a magnetic bead. Biophys J 88(2):1489-1495. https://doi.org/10.1529/biophysj.104. 048157

78. Chan V, Jeong JH, Bajaj P et al (2012) Multi-material bio-fabrication of hydrogel cantilevers and actuators with stereolithography. Lab Chip 12(1):88-98. https://doi.org/10.1039/c1lc20688e

79. Chan V, Park K, Collens MB et al (2012) Development of miniaturized walking biological machines. Sci Rep 2:857. https://doi. org/10.1038/srep00857

80. Nawroth JC, Lee H, Feinberg AW et al (2012) A tissue-engineered jellyfish with biomimetic propulsion. Nat Biotechnol 30(8):792-797. https://doi.org/10.1038/nbt.2269

81. Park SJ, Gazzola M, Park KS et al (2016) Phototactic guidance of a tissue-engineered soft-robotic ray. Science 353(6295):158. https://doi.org/10.1126/science.aaf4292

82. Wang H, Zhao Z, Liu YX et al (2018) Biomimetic enzyme cascade reaction system in microfluidic electrospray microcapsules. Sci Adv 4(6):7. https://doi.org/10.1126/sciadv.aat2816

83. Xu YS, Wang H, Chen BA et al (2019) Emerging barcode particles for multiplex bioassays. Sci China Mater 62(3):289-324. https://doi.org/10.1007/s40843-018-9330-5

84. Wang H, Liu YX, Chen ZY et al (2020) Anisotropic structural color particles from colloidal phase separation. Sci Adv 6(2):9. https://doi.org/10.1126/sciadv.aay1438
85. Kabumoto K, Hoshino T, Akiyama Y et al (2013) Voluntary movement controlled by the surface EMG signal for tissueengineered skeletal muscle on a gripping tool. Tissue Eng Part A 19(15-16):1695-1703. https://doi.org/10.1089/ten.tea.2012. 0421

86. Morimoto Y, Onoe H, Takeuchi S (2018) Biohybrid robot powered by an antagonistic pair of skeletal muscle tissues. Sci Robot 3(18):eaat4440. https://doi.org/10.1126/scirobotics.aat4440

87. Ruan JL, Tulloch NL, Razumova MV et al (2016) Mechanical stress conditioning and electrical stimulation promote contractility and force maturation of induced pluripotent stem cell-derived human cardiac tissue. Circulation 134(20):1557-1598. https:// doi.org/10.1161/circulationaha.114.014998

88. Bian W, Bursac N (2012) Soluble miniagrin enhances contractile function of engineered skeletal muscle. Faseb J 26(2):955-965. https://doi.org/10.1096/fj.11-187575

89. Bian W, Juhas M, Pfeiler TW et al (2012) Local tissue geometry determines contractile force generation of engineered muscle networks. Tissue Eng Part A 18(9-10):957-967. https://doi.org/ 10.1089/ten.TEA.2011.0313

90. Cvetkovic C, Raman R, Chan V et al (2014) Three-dimensionally printed biological machines powered by skeletal muscle. PNAS 111(28):10125-10130. https://doi.org/10.1073/pnas.1401577111

91. Raman R, Cvetkovic C, Bashir R (2017) A modular approach to the design, fabrication, and characterization of muscle-powered biological machines. Nat Protoc 12(3):519-533. https://doi.org/ 10.1038/nprot.2016.185

92. Kim TH, Kwon CH, Lee C et al (2016) Bio-inspired hybrid carbon nanotube muscles. Sci Rep 6:26687. https://doi.org/10.1038/ srep26687

93. Chan V, Neal DM, Uzel SGM et al (2015) Fabrication and characterization of optogenetic, multi-strip cardiac muscles. Lab Chip 15(10):2258-2268. https://doi.org/10.1039/c5lc00222b

94. Kamm RD, Bashir R (2014) Creating living cellular machines. Ann Biomed Eng 42(2):445-459. https://doi.org/10.1007/ s10439-013-0902-7

95. Aydin O, Zhang XT, Nuethong S et al (2019) Neuromuscular actuation of biohybrid motile bots. PNAS 116(40):19841-19847. https://doi.org/10.1073/pnas.1907051116

96. Aydin O, Passaro AP, Elhebeary M et al (2020) Development of 3D neuromuscular bioactuators. APL Bioeng 4(1):016107. https://doi.org/10.1063/1.5134477

97. Devalla HD, Passier R (2018) Cardiac differentiation of pluripotent stem cells and implications for modeling the heart in health and disease. Sci Transl Med 10(435):13. https://doi.org/10.1126/ scitranslmed.aah5457

98. Tanaka Y, Morishima K, Shimizu T et al (2006) An actuated pump on-chip powered by cultured cardiomyocytes. Lab Chip 6(3):362-368. https://doi.org/10.1039/b515149j

99. Tanaka Y, Sato K, Shimizu T et al (2007) A micro-spherical heart pump powered by cultured cardiomyocytes. Lab Chip 7(2):207212. https://doi.org/10.1039/b612082b

100. Tanaka Y, Fujita H (2015) Fluid driving system for a micropump by differentiating iPS cells into cardiomyocytes on a tent-like structure. Sens Actuators B Chem 210:267-272. https://doi.org/ 10.1016/j.snb.2014.12.069

101. Ricotti L, Trimmer B, Feinberg AW et al (2017) Biohybrid actuators for robotics: a review of devices actuated by living cells. Sci Robot 2(12):eaaq495. https://doi.org/10.1126/scirobotics.aaq04 95

102. Akiyama Y, Iwabuchi K, Furukawa Y et al (2009) Long-term and room temperature operable bioactuator powered by insect dorsal vessel tissue. Lab Chip 9(1):140-144. https://doi.org/10. 1039/b809299k

103. Akiyama Y, Odaira K, Sakiyama K et al (2012) Rapidly-moving insect muscle-powered microrobot and its chemical acceleration. 
Biomed Microdev 14(6):979-986. https://doi.org/10.1007/ s10544-012-9700-5

104. Kim J, Park J, Yang S et al (2007) Establishment of a fabrication method for a long-term actuated hybrid cell robot. Lab Chip 7(11):1504-1508. https://doi.org/10.1039/b705367c

105. Akiyama Y, Sakuma T, Funakoshi K et al (2013) Atmosphericoperable bioactuator powered by insect muscle packaged with medium. Lab Chip 13(24):4870-4880. https://doi.org/10.1039/ c31c50490e

106. Williams BJ, Anand SV, Rajagopalan J et al (2014) A self-propelled biohybrid swimmer at low Reynolds number. Nat Commun 5:8. https://doi.org/10.1038/ncomms4081

107. Shi XD, Shi ZJ, Wang DM et al (2016) Microbial cells with a $\mathrm{Fe}_{3} \mathrm{O}_{4}$ doped hydrogel extracellular matrix: manipulation of living cells by magnetic stimulus. Macromol Biosci 16(10):15061514. https://doi.org/10.1002/mabi.201600143

108. Edwards MR, Carlsen RW, Sitti M (2013) Near and far-wall effects on the three-dimensional motion of bacteria-driven microbeads. Appl Phys Lett 102(14):4. https://doi.org/10.1063/1.48018 10

109. Molaei M, Barry M, Stocker R et al (2014) Failed escape: solid surfaces prevent tumbling of Escherichia coli. Phys Rev Lett 113(6):6. https://doi.org/10.1103/PhysRevLett.113.068103

110. Schwarz L, Medina-Sanchez M, Schmidt OG (2017) Hybrid biomicromotors. Appl Phys Rev 4(3):23. https://doi.org/10. 1063/1.4993441

111. Park SJ, Park SH, Cho S et al (2013) New paradigm for tumor theranostic methodology using bacteria-based microrobot. Sci Rep 3:8. https://doi.org/10.1038/srep03394

112. Nguyen VD, Han JW, Choi YJ et al (2016) Active tumor-therapeutic liposomal bacteriobot combining a drug (paclitaxel)encapsulated liposome with targeting bacteria (Salmonella Typhimurium). Sens Actuators B Chem 224:217-224. https:// doi.org/10.1016/j.snb.2015.09.034

113. Carlsen RW, Edwards MR, Zhuang J et al (2014) Magnetic steering control of multi-cellular bio-hybrid microswimmers. Lab Chip 14(19):3850-3859. https://doi.org/10.1039/c4lc0 $0707 \mathrm{~g}$

114. Arrieta J, Barreira A, Chioccioli M et al (2017) Phototaxis beyond turning: persistent accumulation and response acclimation of the microalga Chlamydomonas reinhardtii. Sci Rep 7:7. https://doi.org/10.1038/s41598-017-03618-8

115. Xie SX, Jiao ND, Tung $S$ et al (2016) Novel algae guiding system to robotize algae cells. IEEE 3M-NANO-IEEE Int Conf Manip, Manuf Meas Nanoscale, pp 64-68. https://doi. org/10.1109/3M-NANO.2016.7824669

116. Zhuang J, Park BW, Sitti M (2017) Propulsion and chemotaxis in bacteria-driven microswimmers. Adv Sci 4(9):12. https:// doi.org/10.1002/advs.201700109

117. Barroso A, Landwerth S, Woerdemann M et al (2015) Optical assembly of bio-hybrid micro-robots. Biomed Microdev 17(2):8. https://doi.org/10.1007/s10544-015-9933-1

118. Singh AV, Sitti M (2016) Patterned and specific attachment of bacteria on biohybrid bacteria-driven microswimmers. Adv Healthc Mater 5(18):2325-2331. https://doi.org/10.1002/ adhm.201600155

119. Park SJ, Lee YK, Cho S et al (2015) Effect of chitosan coating on a bacteria-based alginate microrobot. Biotechnol Bioeng 112(4):769-776. https://doi.org/10.1002/bit.25476

120. Xie SX, Jiao ND, Tung $S$ et al (2016) Controlled regular locomotion of algae cell microrobots. Biomed Microdev 18(3):9. https://doi.org/10.1007/s10544-016-0074-y

121. Yasa O, Erkoc P, Alapan Y et al (2018) Microalga-powered microswimmers toward active cargo delivery. Adv Mater 30(45):10. https://doi.org/10.1002/adma.201804130
122. Singh AV, Hosseinidoust Z, Park BW et al (2017) Microemulsion-based soft bacteria-driven microswimmers for active cargo delivery. ACS Nano 11(10):9759-9769. https://doi.org/ 10.1021/acsnano.7b02082

123. Stanton MM, Park BW, Miguel-Lopez A et al (2017) Biohybrid microtube swimmers driven by single captured bacteria. Small 13(19):10. https://doi.org/10.1002/smll.201603679

124. Zhuang J, Sitti M (2016) Chemotaxis of bio-hybrid multiple bacteria-driven microswimmers. Sci Rep 6:10. https://doi.org/ $10.1038 /$ srep32135

125. Park BW, Zhuang J, Yasa O et al (2017) Multifunctional bacteria-driven microswimmers for targeted active drug delivery. ACS Nano 11(9):8910-8923. https://doi.org/10.1021/acsnano. $7 \mathrm{~b} 03207$

126. Buss N, Yasa O, Alapan Y et al (2020) Nanoerythrosomefunctionalized biohybrid microswimmers. APL Bioeng 4(2):026103. https://doi.org/10.1063/1.5130670

127. Tanaka Y, Noguchi Y, Yalikun Y et al (2017) Earthworm muscle driven bio-micropump. Sens Actuators B Chem 242:11861192. https://doi.org/10.1016/j.snb.2016.09.123

128. Loverich JJ, Kanno I, Kotera H (2006) Concepts for a new class of all-polymer micropumps. Lab Chip 6(9):1147-1154. https:// doi.org/10.1039/b605525g

129. Jo C, Pugal D, Oh IK et al (2013) Recent advances in ionic polymer-metal composite actuators and their modeling and applications. Prog Polym Sci 38(7):1037-1066. https://doi.org/10. 1016/j.progpolymsci.2013.04.003

130. Xia F, Tadigadapa S, Zhang QM (2006) Electroactive polymer based microfluidic pump. Sens Actuator A Phys 125(2):346-352. https://doi.org/10.1016/j.sna.2005.06.026

131. Khalil ISM, Klingner A, Magdanz V et al (2019) Modeling of spermbots in a viscous colloidal suspension. Adv Theory Simul 2(8):11. https://doi.org/10.1002/adts.201900072

132. Khalil ISM, Magdanz V, Simmchen J et al (2020) Resemblance between motile and magnetically actuated sperm cells. Appl Phys Lett 116(6):5. https://doi.org/10.1063/1.5142470

133. Han J, Zhen J, Nguyen VD et al (2016) Hybrid-actuating macrophage-based microrobots for active cancer therapy. Sci Rep 6:10. https://doi.org/10.1038/srep28717

134. Distler T, Solisito AA, Schneidereit D et al (2020) 3D printed oxidized alginate-gelatin bioink provides guidance for $\mathrm{C} 2 \mathrm{C} 12$ muscle precursor cell orientation and differentiation via shear stress during bioprinting. Biofabrication 12(4):045005. https:// doi.org/10.1088/1758-5090/ab98e4

135. Sun T, Shi Q, Liang Q et al (2020) Fabrication of vascular smooth muscle-like tissues based on self-organization of circumferentially aligned cells in microengineered hydrogels. Lab Chip 20(17):3120-3131. https://doi.org/10.1039/d01c00544d

136. Kim J, Hayward RC (2012) Mimicking dynamic in vivo environments with stimuli-responsive materials for cell culture. Trends Biotechnol 30(8):426-439. https://doi.org/10.1016/j.tibtech. 2012.04.003

137. Anand SV, Yakut Ali M, Saif MT (2015) Cell culture on microfabricated one-dimensional polymeric structures for bio-actuator and bio-bot applications. Lab Chip 15(8):1879-1888. https://doi. org/10.1039/c4lc01471e

138. Vannozzi L, Ricotti L, Cianchetti M et al (2015) Self-assembly of polydimethylsiloxane structures from $2 \mathrm{D}$ to $3 \mathrm{D}$ for bio-hybrid actuation. Bioinspir Biomim 10(5):16. https://doi.org/10.1088/ 1748-3190/10/5/056001

139. Lind JU, Busbee TA, Valentine AD et al (2017) Instrumented cardiac microphysiological devices via multimaterial threedimensional printing. Nat Mater 16(3):303-309. https://doi.org/ $10.1038 /$ nmat4782

140. Abadi P, Garbern JC, Behzadi S et al (2018) Engineering of mature human induced pluripotent stem cell-derived 
cardiomyocytes using substrates with multiscale topography. Adv Funct Mater 28(19):11. https://doi.org/10.1002/adfm.201707378

141. Lam T, Dehne T, Kruger JP et al (2019) Photopolymerizable gelatin and hyaluronic acid for stereolithographic 3D bioprinting of tissue-engineered cartilage. J Biomed Mater Res Part B 107(8):2649-2657. https://doi.org/10.1002/jbm.b.34354

142. Roshanbinfar K, Mohammadi Z, Mesgar ASM et al (2019) Carbon nanotube doped pericardial matrix derived electroconductive biohybrid hydrogel for cardiac tissue engineering. Biomater Sci 7(9):3906-3917. https://doi.org/10.1039/c9bm00434c

143. Annabi N, Selimovic S, Cox JPA et al (2013) Hydrogel-coated microfluidic channels for cardiomyocyte culture. Lab Chip 13(18):3569-3577. https://doi.org/10.1039/c3lc50252j

144. Ramon-Azcon J, Ahadian S, Estili M et al (2013) Dielectrophoretically aligned carbon nanotubes to control electrical and mechanical properties of hydrogels to fabricate contractile muscle myofibers. Adv Mater 25(29):4028-4034. https://doi.org/10. 1002/adma.201301300

145. Hahn MS, Taite LJ, Moon JJ et al (2006) Photolithographic patterning of polyethylene glycol hydrogels. Biomaterials 27(12):2519-2524. https://doi.org/10.1016/j.biomaterials. 2005.11.045

146. Suh KY, Seong J, Khademhosseini A et al (2004) A simple soft lithographic route to fabrication of poly(ethylene glycol) microstructures for protein and cell patterning. Biomaterials 25(3):557-563. https://doi.org/10.1016/s0142-9612(03) 00543-x

147. Morimoto Y, Onoe H, Takeuchi S (2019) Biohybrid device with antagonistic skeletal muscle tissue for measurement of contractile force. Adv Robot 33(5):208-218. https://doi.org/10.1080/ 01691864.2019.1567382

148. Cvetkovic C, Rich MH, Raman R et al (2017) A 3D-printed platform for modular neuromuscular motor units. Microsyst Nanoeng 3:9. https://doi.org/10.1038/micronano.2017.15

149. Raman R, Grant L, Seo Y et al (2017) Damage, healing, and remodeling in optogenetic skeletal muscle bioactuators. Adv Healthc Mater 6(12):1700030. https://doi.org/10.1002/adhm. 201700030

150. Zhang C, Wang JY, Wang WX et al (2016) Modeling and analysis of bio-syncretic micro-swimmers for cardiomyocyte-based actuation. Bioinspir Biomim 11(5):13. https://doi.org/10.1088/ 1748-3190/11/5/056006

151. Akiyama Y, Hoshino T, Iwabuchi K et al (2012) Room temperature operable autonomously moving bio-microrobot powered by insect dorsal vessel tissue. PLoS ONE 7(7):6. https://doi.org/10. 1371/journal.pone.0038274

152. Feinberg AW, Feigel A, Shevkoplyas SS et al (2007) Muscular thin films for building actuators and powering devices. Science 317(5843):1366-1370. https://doi.org/10.1126/science.1146885

153. Shutko AV, Gorbunov VS, Guria KG et al (2017) Biocontractile microfluidic channels for peristaltic pumping. Biomed Microdev 19(4):6. https://doi.org/10.1007/s10544-017-0216-x

154. Lee A, Hudson AR, Shiwarski DJ et al (2019) 3D bioprinting of collagen to rebuild components of the human heart. Science 365(6452):482. https://doi.org/10.1126/science.aav9051

155. Kang HW, Lee SJ, Ko IK et al (2016) A 3D bioprinting system to produce human-scale tissue constructs with structural integrity. Nat Biotechnol 34(3):312-319. https://doi.org/10.1038/nbt.3413

156. Sonntag L, Simmchen J, Magdanz V (2019) Nano- and micromotors designed for cancer therapy. Molecules 24(18):34. https:// doi.org/10.3390/molecules24183410

157. Davidson MD, Ban E, Schoonen ACM et al (2020) Mechanochemical adhesion and plasticity in multifiber hydrogel networks. Adv Mater 32(8):8. https://doi.org/10.1002/adma.201905719

158. Shin SR, Jung SM, Zalabany M et al (2013) Carbon-nanotubeembedded hydrogel sheets for engineering cardiac constructs and bioactuators. ACS Nano 7(3):2369-2380. https://doi.org/ $10.1021 / \mathrm{nn} 305559 \mathrm{j}$

159. Yoon J, Eyster TW, Misra AC et al (2015) Cardiomyocyte-driven actuation in biohybrid microcylinders. Adv Mater 27(30):45094515. https://doi.org/10.1002/adma.201501284

160. Liu X, Zhao H, Lu YX et al (2016) In vitro cardiomyocytedriven biogenerator based on aligned piezoelectric nanofibers. Nanoscale 8(13):7278-7286. https://doi.org/10.1039/c5nr08430j

161. Park J, Kim IC, Baek J et al (2007) Micro pumping with cardiomyocyte-polymer hybrid. Lab Chip 7(10):1367-1370. https:// doi.org/10.1039/b703900j

162. Tanaka Y, Sato K, Shimizu T et al (2008) Demonstration of a biomicroactuator powered by vascular smooth muscle cells coupled to polymer micropillars. Lab Chip 8(1):58-61. https://doi.org/10. 1039/b714252h

163. Williams BJ, Anand SV, Rajagopalan J et al (2014) A microfabricated, biohybrid, soft robotics flagellum. In: Proceedings of the IEEE 27th international conference on micro electro mechanical systems, pp 192-195. https://doi.org/10.1109/MEMSYS.2014. 6765607

164. Shin SR, Shin C, Memic A et al (2015) Aligned carbon nanotubebased flexible gel substrates for engineering biohybrid tissue actuators. Adv Funct Mater 25(28):4486-4495. https://doi.org/ 10.1002/adfm.201501379

165. Shin SR, Migliori B, Miccoli B et al (2018) Electrically driven microengineered bioinspired soft robots. Adv Mater 30(10):1704189. https://doi.org/10.1002/adma.201704189

166. McCain ML, Agarwal A, Nesmith HW et al (2014) Micromolded gelatin hydrogels for extended culture of engineered cardiac tissues. Biomaterials 35(21):5462-5471. https://doi.org/10.1016/j. biomaterials.2014.03.052

167. Fu FF, Shang LR, Chen ZY et al (2018) Bioinspired living structural color hydrogels. Sci Robot 3(16):8. https://doi.org/10.1126/ scirobotics.aar8580

168. Hinds S, Bian W, Dennis RG et al (2011) The role of extracellular matrix composition in structure and function of bioengineered skeletal muscle. Biomaterials 32(14):3575-3583. https://doi.org/ 10.1016/j.biomaterials.2011.01.062

169. Sakar MS, Neal D, Boudou T et al (2012) Formation and optogenetic control of engineered 3D skeletal muscle bioactuators. Lab Chip 12(23):4976-4985. https://doi.org/10.1039/c2lc40338b

170. Webster VA, Hawley EL, Akkus O et al (2015) Fabrication of electrocompacted aligned collagen morphs for cardiomyocyte powered living machines. Lect Notes Comput Sci. https://doi. org/10.1007/978-3-319-22979-9_43

171. Liu LQ, Zhang C, Wang WX et al (2018) Regulation of C2C12 differentiation and control of the beating dynamics of contractile cells for a muscle-driven biosyncretic crawler by electrical stimulation. Soft Robot 5(6):748-760. https://doi.org/10.1089/ soro.2018.0017

172. Kim Y, Pagan-Diaz G, Gapinske L et al (2020) Integration of graphene electrodes with 3D skeletal muscle tissue models. Adv Healthc Mater 9(4):6. https://doi.org/10.1002/adhm.201901137

173. Alapan Y, Yasa O, Schauer O et al (2018) Soft erythrocyte-based bacterial microswimmers for cargo delivery. Sci Robot 3(17):10. https://doi.org/10.1126/scirobotics.aar4423

174. Webster VA, Chapin KJ, Hawley EL et al (2016) Aplysia Californica as a novel source of material for biohybrid robots and organic machines I. Lect Notes Comput Sci. https://doi.org/10. 1007/978-3-319-42417-0_33

175. Stanton MM, Simmchen J, Ma X et al (2016) Biohybrid Janus motors driven by Escherichia coli. Adv Mater Interf 3(2):8. https://doi.org/10.1002/admi.201500505

176. Donnelly K, Khodabukus A, Philp A et al (2010) A novel bioreactor for stimulating skeletal muscle in vitro. Tissue Eng Part 
C-Methods 16(4):711-718. https://doi.org/10.1089/ten.tec.2009. 0125

177. Ahadian S, Ostrovidov S, Hosseini V et al (2013) Electrical stimulation as a biomimicry tool for regulating muscle cell behavior. Organogenesis 9(2):87-92. https://doi.org/10.4161/org.25121

178. Rangarajan S, Madden L, Bursac N (2014) Use of flow, electri$\mathrm{cal}$, and mechanical stimulation to promote engineering of striated muscles. Ann Biomed Eng 42(7):1391-1405. https://doi. org/10.1007/s10439-013-0966-4

179. Asano T, Ishizuka T, Morishima K et al (2015) Optogenetic induction of contractile ability in immature $\mathrm{C} 2 \mathrm{C} 12$ myotubes. Sci Rep 5:8. https://doi.org/10.1038/srep08317

180. Hernandez D, Millard R, Sivakumaran P et al (2016) Electrical stimulation promotes cardiac differentiation of human induced pluripotent stem cells. Stem Cells Int 2016:12. https://doi.org/ 10.1155/2016/1718041

181. Thrivikraman G, Boda SK, Basu B (2018) Unraveling the mechanistic effects of electric field stimulation towards directing stem cell fate and function: a tissue engineering perspective. Biomaterials 150:60-86. https://doi.org/10.1016/j.biomaterials.2017. 10.003

182. Vizsnyiczai G, Frangipane G, Maggi C et al (2017) Light controlled 3D micromotors powered by bacteria. Nat Commun 8:7. https://doi.org/10.1038/ncomms15974

183. Magdanz V, Guix M, Hebenstreit F et al (2016) Dynamic polymeric microtubes for the remote-controlled capture, guidance, and release of sperm cells. Adv Mater 28(21):4084-4089. https:// doi.org/10.1002/adma.201505487

184. Uesugi K, Shimizu K, Akiyama Y et al (2016) Contractile performance and controllability of insect muscle-powered bioactuator with different stimulation strategies for soft robotics. Soft Robot 3(1):13-22. https://doi.org/10.1089/soro.2015.0014

185. Zhuang J, Carlsen RW, Sitti M (2015) pH-taxis of biohybrid microsystems. Sci Rep 5:13. https://doi.org/10.1038/srep11403 